\title{
INFLUENCES OF ANTHROPOGENIC NOISE ON FLIGHT INITIATION DISTANCE, FORAGING BEHAVIOR, AND FEEDER COMMUNITY STRUCTURE OF WILD BIRDS
}

\author{
A Thesis \\ presented to \\ the Faculty of California Polytechnic State University, \\ San Luis Obispo \\ In Partial Fulfillment \\ of the Requirements for the Degree \\ Master of Science in Biology
}

by

Alissa Petrelli Graunke

December 2017 
(C) 2017

Alissa Petrelli Graunke

ALL RIGHTS RESERVED 


\section{COMMITTEE MEMBERSHIP}

TrTLE: Influences of Anthropogenic Noise on Flight

Initiation Distance, Foraging Behavior, And

Feeder Community Structure of Wild Birds

AUTHOR: $\quad$ Alissa Petrelli Graunke

DATE SubMITTED: December 2017

Committee Chair: $\quad$ Clinton Francis, Ph.D.

Assistant Professor of Biology

Committee Member: $\quad$ Gita Kolluru, Ph.D.

Associate Professor of Biology

Committee Member: $\quad$ Crow White, Ph.D.

Assistant Professor of Biology 


\begin{abstract}
Influences of Anthropogenic Noise on Flight Initiation Distance, Foraging Behavior, And Feeder Community Structure of Wild Birds
\end{abstract}

Alissa Petrelli Graunke

Throughout the world, birds represent the primary type of wildlife that people experience on a daily basis. However, a growing body of evidence suggests that alterations to the acoustic environment can negatively affect birds as well as humans in a variety of ways, and altered acoustics from noise pollution has the potential to influence human interactions with wild birds. In this thesis, I investigated how anthropogenic noise impacts daily behavior as well as community structure of wild birds. In the first component of this thesis, I assessed the distance at which a bird initiates flight or escape behavior (i.e., flight initiation distance or FID) in varying acoustic conditions. I surveyed 12 songbird species from three foraging guilds, ground foragers, canopy gleaners, and hawking flycatchers, and I predicted FIDs to decrease, remain the same, and increase with noise exposure, respectively. Contrary to expectations, the canopy gleaning and flycatching guilds exhibited mixed responses, with some species exhibiting unchanged FIDs with noise while others exhibited increased FIDs with noise. However, FIDs of all ground foraging species and one canopy gleaner decreased with noise levels. In the second component, I examined the feeding of wild birds, an increasingly popular recreational activity throughout North America that promotes increased sense of wellbeing by connecting people with wildlife and nature. I tested how experimental noise influences abundance, species richness, community structure and foraging behavior of songbirds at maintained bird feeders. By measuring activity levels of all species that 
utilized the feeders exposed to intervals of quiet and noisy conditions, I found noise to be a significant predictor of community turnover. Specifically, noise exposure resulted in increased feeder activity for two species, and decreased activity for one species. I also confirmed previous research conducted in the laboratory indicating white-crowned sparrows decrease their foraging rate under noise conditions, presumably as a trade off with visual vigilance. Considering the interactions of humans and wild birds, the results from my two thesis components indicate that the acoustic environment can play a role in how species of different foraging guilds respond to birdwatchers and what species visit bird feeders.

Keywords: anthropogenic noise, flight initiation distance, behavior, foraging, bird feeder, community structure 


\section{ACKNOWLEDGMENTS}

I would like to thank the National Science Foundation and the Aryan I. Roest Memorial Scholarship for the generous funding they provided. I would also like to thank Steve Schubert and the staff of the Kern Environmental Education Program for providing their campus as a study site. This research would not have been possible without the diligent field work of Ryan Wardle and Mitchell Levenhagen. Thank you to Dr. Jesse Barber, who helped with project creation and publication. Thanks to my committee members Drs. Gita Kolluru and Crow White for their guidance in experimental design and their feedback on early thesis drafts. I would also like to thank the office staff, IT staff, and graduate and undergraduate students of Cal Poly Biological Sciences, who provided assistance and support on many occasions. A special thank you to Clinton Francis for his mentoring, guidance, and friendship throughout the past three years. Finally, this thesis would not be possible without the encouragement of my friends and family and the unwavering support of my husband, Andrew Graunke. 
LIST OF

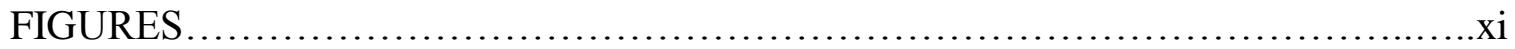

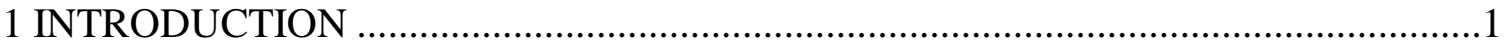

2 EFFECTS OF ANTHROPOGENIC NOISE ON FLIGHT INITIATION DISTANCE

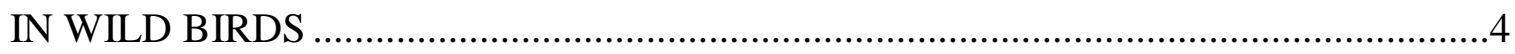

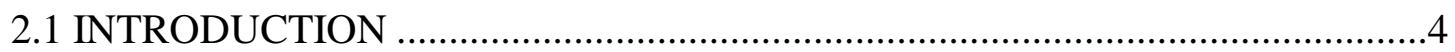

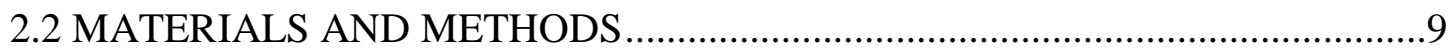

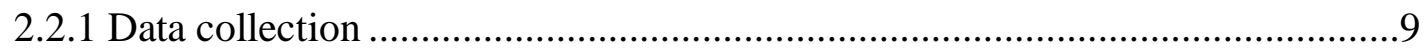

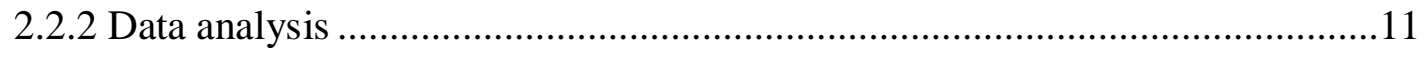

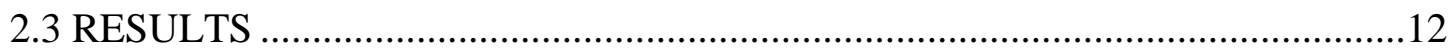

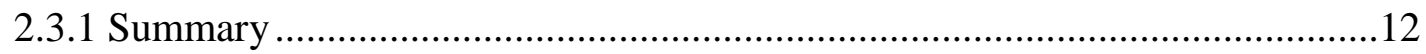

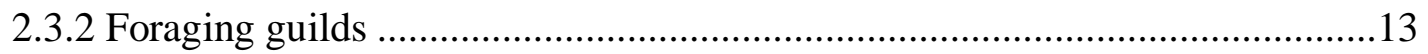

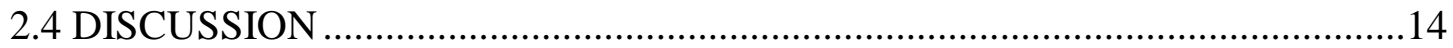

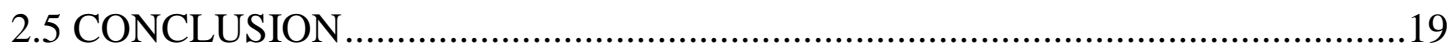

3. EFFECTS OF ANTHROPOGENIC NOISE ON AVIAN FEEDER COMMUNITY

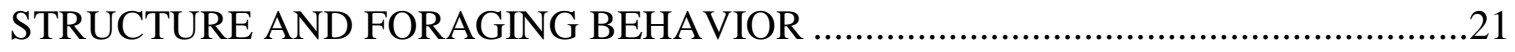

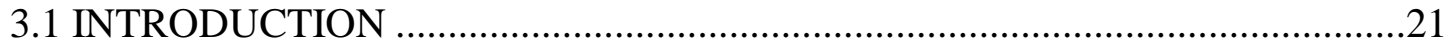

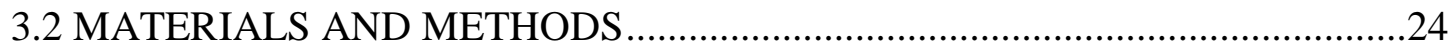

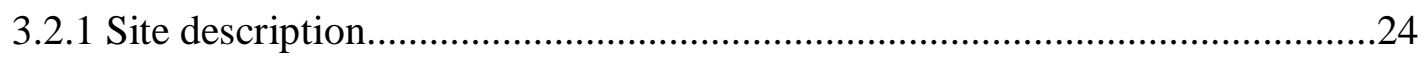

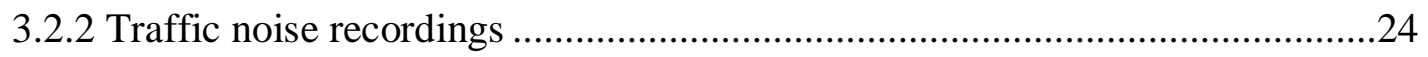




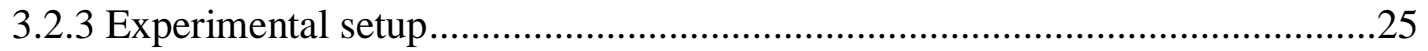

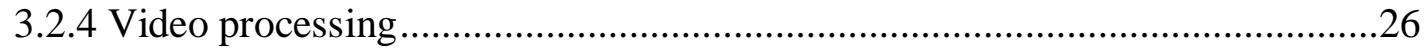

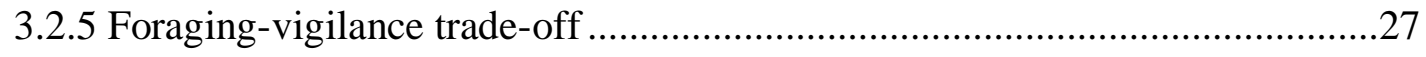

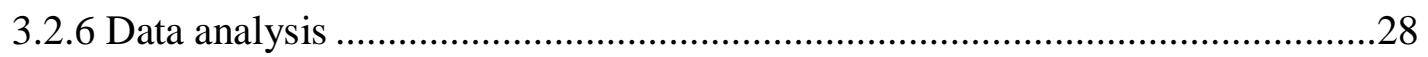

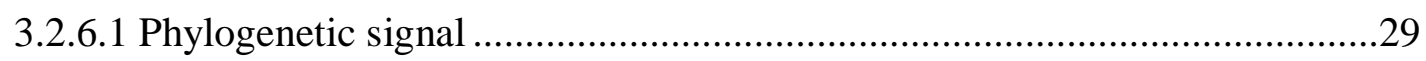

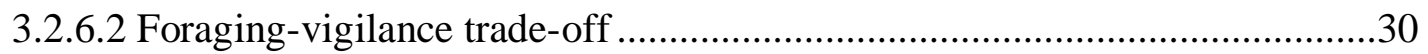

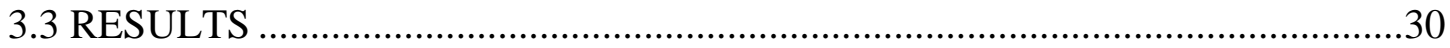

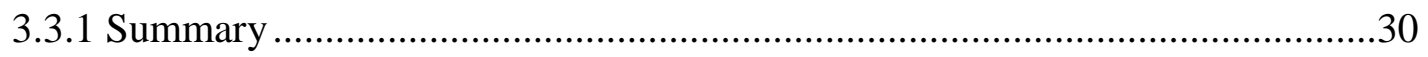

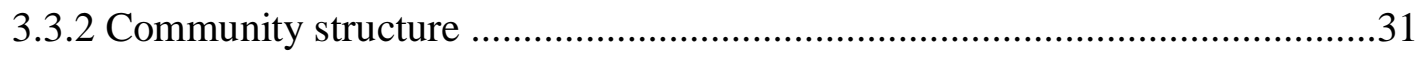

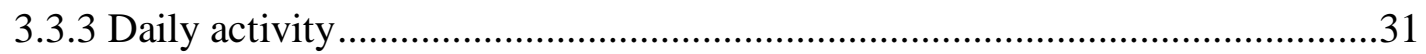

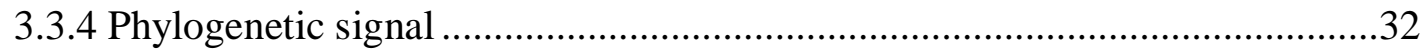

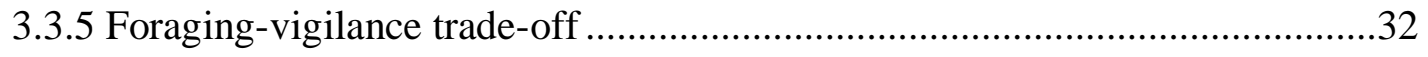

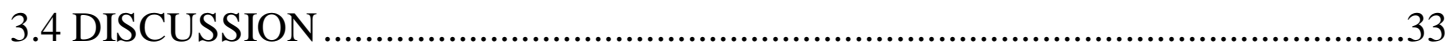

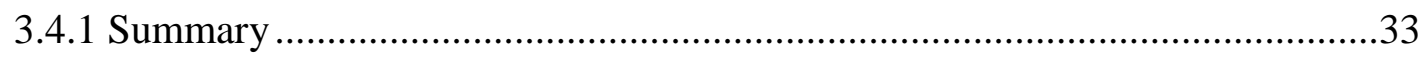

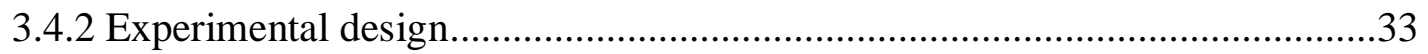

3.4.3 Species activity levels and community turnover ...................................... 34

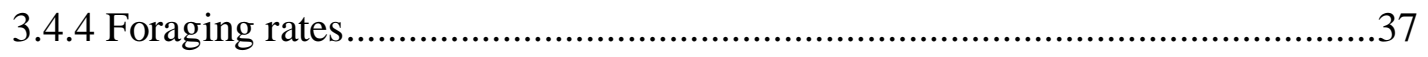

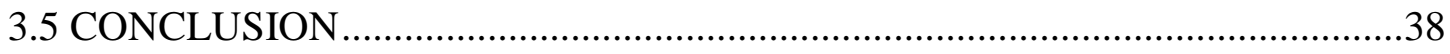

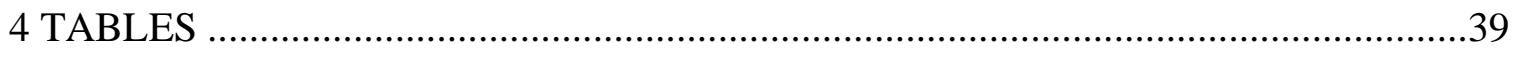

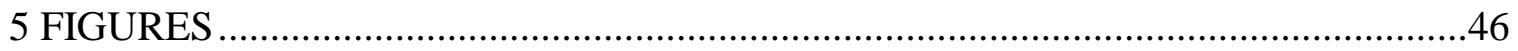


REFERENCES

APPENDIX 


\section{LIST OF TABLES}

Table

Page

Table 1: We observed 196 individuals from 12 songbird species and grouped the species into three foraging guilds.

Table 2: Model selection table reports all the models within 2.00 $\triangle \mathrm{AICc}$ in addition to the null model (intercept only) for each foraging guild. .40

Table 3: The influence of fixed effects on adjusted FID for ground foraging species .41

Table 4: The output for a linear mixed effect model of the canopy gleaning guild .42

Table 5: The output for a linear mixed effect model of the flycatching guild .43

Table 6: This model selection table reports all the models for dark-eyed junco pecking rate within $2.00 \Delta \mathrm{AICc}$

Table 7: Model selection table reporting all the models for white-crowned sparrow pecking rate within $2.00 \Delta \mathrm{AICc}$, plus the null .45

Table A1: This table summarizes the effect of sound level and foraging guild-specific competition on species-specific daily activity.

Table A2: This fixed effects table reports the influence of given variables on pecking rate of dark-eyed juncos. 


\section{LIST OF FIGURES}

Figures $\quad$ Page

Figure 1: Predicted responses for three foraging guilds of songbirds ..........................46

Figure 2: Panel A illustrates different intercepts to the slope depicted in panel B for each species in the ground foraging guild ....................................................4

Figure 3: Satellite image of Camp KEEP campus, an area of approximately 1 hectare....48

Figure 4: The daily average LEQ measurements during experimental noise exposure and ambient conditions differed significantly.

Figure 5: Average sound levels at the four feeder sites across the entire experiment differed significantly by treatment, with the noisiest conditions at Site A for quiet (lower darker boxes) and noise exposure (higher lighter boxes)

Figure 6: This three-dimensional nonmetric multidimensional scaling plot visualizes the avian communities of four different feeder sites

Figure 7: Value and direction of the effect of sound level on the daily activity for each species in our study. Bars represent $95 \%$ confidence intervals and bars that do not cross the 0 axis indicate significant effects of noise on species activity ........52

Figure 8: Pecking rate of white-crowned sparrows in relation to background sound level $(\mathrm{dB}(\mathrm{A}))$. The shaded band represents a $95 \%$ confidence interval. 


\section{INTRODUCTION}

Soundscapes can be defined as the acoustic environment a listener perceives (Francis et al. 2017). Terrestrial soundscapes include abiotic factors like moving water and wind as well as biotic factors like animal vocalizations. For the past 50 million years, terrestrial soundscapes have been dominated by sounds produced by insects (Gill et al. 2007; Senter et al. 2008). However, human activity in the past 200 years has generated anthropogenic noise that has increasingly replaced natural sounds. Myriad reports indicate that these human-dominated soundscapes have negative impacts on ecological systems as well as human wellbeing (Barber et al. 2010; Francis et al. 2017).

Considering the evolutionary context of natural soundscapes, the importance of natural sounds in the daily lives of wild animals deserves recognition. Most animals rely on their sense of hearing as they communicate and perceive their environment, for example listening for vocalizations of potential mates or detecting a source of flowing water (Francis \& Barber 2013). Similarly, humans have been shown to positively respond to natural sounds: increased sense of wellbeing, improved stress recovery, attention restoration, and connection with nature (Abbott et al. 2016; Ratcliffe et al. 2013; Ulrich et al. 1991). However, anthropogenic sounds have been shown to negatively impact both humans and wildlife. In humans, chronic noise exposure is associated with increased risk of cardiovascular disease, decreases in memory and mood state, and compromised learning in children (Benfield et al. 2010; Benfield et al. 2014; Stansfeld et al. 2005; van Kempen and Babisch 2012). For wildlife, altered behavior, distributions, and reproductive success are known consequences of anthropogenic noise due to its interference with animals' abilities to hear (Francis \& Barber 2013). 
Understanding these responses to anthropogenic noise can be clarified through the concept of a listening area, defined as the region within which a listener (animal or human) can detect and discriminate auditory cues (Barber et al. 2010). Increases in background sound effectively reduce this listening area, thus, in noisy environments, listeners can perceive signals from only a portion of their total environment. Acoustical physics predicts that an increase of three decibels in background noise will reduce an individual's listening area by half (Kaplan \& Kaplan 1989). This severe reduction in listening area is potentially impacting wildlife across the country. A recent survey of continental-scale noise patterns reports that over $80 \%$ of the contiguous United States experiences sound levels that are elevated above ambient due to anthropogenic sources (Mennitt et al. 2013). Noise pollution even spreads to natural areas; 63\% of US protected areas have been shown to experience doubled sound levels due to anthropogenic activity such as transportation and development (Buxton et al. 2017). In these areas, wildlife can respond to noise through altering behavior or avoiding areas altogether (Bayne et al. 2008; Francis 2015; McClure et al. 2013). Considering that opportunities to experience wildlife is a leading motivation for people to visit protected areas, these influences of noise on wildlife can indirectly impact human visitors. Furthermore, humans also experience a reduction of listening area in the presence of background noise, resulting in lessened ability to acoustically detect wildlife and potentially negative overall experience.

This thesis focuses on the interaction between humans and wildlife in the context of the acoustic environment. Francis et al. (2017) proposed a framework for utilizing the bridge between human and natural systems as a focus for conservation efforts. Here, I focus on birds as a type of wildlife that humans encounter on a daily basis. Importantly, 
birdsong represents a type of natural sound that humans experience regularly. In the United States, both birdwatching and bird feeding are increasingly popular recreation activity where humans interact with wild birds and have the opportunity to connect with nature (La Rouch et al. 2006; US Fish \& Wildlife 2016).

In the first component of my thesis, I explore how anthropogenic noise influences how wild birds perceive birdwatchers as approaching threats. Birds, like all animals, have a limit of how close a threat can approach before initiating escape, a metric known as flight initiation distance. I hypothesize that birds rely on different sensory mechanisms to perceive their environment depending on their primary foraging strategy and, thus, responses to noise pollution will differ between species of different foraging guilds.

In the second component of my thesis, I investigate the influences of noise exposure on bird communities at maintained bird feeders. I hypothesize that most feeder birds will avoid foraging under conditions of noise, resulting in higher activity at quiet feeders. Using this experimental field setup, I also test the laboratory findings of Quinn et al. 2006 and Ware et al. 2015 that indicate birds respond to noise exposure by spending less time foraging and more time visually scanning for predators. I hypothesize that birds foraging at my feeders will demonstrate similar behavioral adjustments in noise.

This research focuses on furthering our understanding of how anthropogenic noise impacts wildlife, humans, and their interactions. The results from these studies can be used to inform management practices in natural areas, where humans often go to seek out experiences with wildlife. Improving awareness of the negative impacts of anthropogenic noise might also inform development of policies to limit noise production and propagation and potentially help restore natural soundscapes across the continent. 


\section{EFFECTS OF ANTHROPOGENIC NOISE ON FLIGHT INITIATION DISTANCE IN WILD BIRDS}

\subsection{INTRODUCTION}

Anthropogenic noise encroaches on many natural landscapes (Barber et al. 2011; Francis et al. 2011; Mennitt et al. 2013). A growing body of research indicates such noise can detrimentally affect wildlife (Barber et al. 2010, Francis and Barber 2013, Shannon et al. 2015) and might create a negative feedback process that degrades humans' experiences of nature (Francis et al. in review). In the context of birdwatching, an increasingly popular recreational activity (La Rouch 2003; Carver 2013), the ability to approach birds in the wild is a valued human experience that may be threatened by anthropogenic noise. Although there is typically a limit to how close a human can approach a wild animal before the animal initiates an escape, the distance at which flight is initiated varies across taxa and could depend on the animal's acoustic environment.

The acoustic environment serves as a critical medium through which many species, including humans, interact with their surroundings. Humans are motivated by natural sounds, such as bird songs and sounds, to seek out and experience natural places (Haas and Wakefield 1998; Marin et al. 2011). Recent work has also demonstrated that listening to birdsong has the potential to enhance personal experiences with nature (Newman et al. 2013), improve stress recovery (Ratcliffe et al. 2013), and renew cognitive abilities after mental exertion (Abbott et al. 2016). In addition to these benefits to casual nature-seekers, birdsong is a valued tool for birdwatchers, who can acoustically localize wild birds for viewing or identification. However, in areas of elevated background sound, an observer's ability to detect birds is constrained by masking, the 
process through which background noise interferes with the perception of an acoustic signal (Pacifici et al. 2008; Ortega and Francis 2012). Like humans, masking by noise can interfere with birds' abilities to detect and discriminate biologically relevant cues. For example, elevated ambient noise may influence how birds detect and respond to the threat of an approaching predator or human observer, which they perceive in the same manner (Frid and Dill 2002). Thus, from the human perspective, where the quality of seeing and hearing a bird can depend upon the proximity of an approach, changes to the acoustic environment could indirectly influence the quality of the human experience with birds through changes in bird behavior.

Broadly speaking, anthropogenic noise can affect wildlife in many ways beyond threat detection (Francis and Barber 2013). Previous research has demonstrated that increased noise can lead to decreased reproductive success (Mulholland et al. in review; Halfwerk et al. 2011, Kight et al. 2012), impact community structure and ecological interactions (Francis et al. 2009), and degrade habitat quality (McClure et al. 2013; Ware et al. 2015; Francis et al. 2009). Most relevant to this study are the many ways that noise affects avian behavior (Shannon et al. 2015), especially aspects of risk assessment and antipredator behavior. Karp and Root (2009) found that free-living hoatzins (Opisthocomus hoazin) increased alertness and flush more quickly when tourists approach while conversing loudly compared to silent approaches. Samia and Blumstein (2015) suggested that escape behavior in birds is largely explained by the flush early and avoid the rush (FEAR) hypothesis, which posits that prey will flee soon after predator detection to avoid costs associated with monitoring the predator. Considering this 
finding, it might be expected that birds should flush quickly unless threat detection is delayed or otherwise impaired due to interfering circumstances.

Flushing behavior is commonly measured as the distance between an observer and an animal when it flushes (termed "flight initiation distance," hereafter FID) and is often used as a proxy for a species' tolerance of predators as well as the presence of humans. Previous studies have determined that species identity, starting distance, individual body size, and vegetation cover are all important predictors of FID (Blumstein 2003, Blumstein et al. 2003, Fernández-Juricic et al. 2002). The influence of noise on FID has been investigated in two non-avian systems. Chan et al. (2010a and 2010b) demonstrated that Caribbean hermit crabs (Coenobita clypeatus) are slower to respond to an intruder when noise is played during the approach. Based on this finding, Chan et al. (2010a) proposed the distracted prey hypothesis, which suggests that animals have finite attention and become distracted from ecologically relevant cues when a stimulus such as background noise occupies some of that attention. Shannon et al. (2016) found the opposite outcome; black-tailed prairie dogs (Cynomys ludovicianus) flushed more quickly when a human intruder approached under higher sound levels generated from speakers broadcasting roadway noise. The prairie dogs in this study were hypervigilant, committing more time to detecting potential threats through visual surveillance when background sound levels were high (Shannon et al. 2016). Birds are also known to increase visual alertness when their auditory abilities are impaired by ambient noise. Quinn et al. (2006) demonstrated that chaffinches (Fringilla coelebs) in a laboratory setting spent more time visually scanning for predators than actively foraging during playbacks of white noise, a stimulus not found in nature, when compared to quiet 
conditions. Ware et al. (2015) confirmed these findings in a study of white-crowned sparrows (Zonotrichia leucophrys) foraging during playbacks of traffic recordings, a stimulus many free-living birds experience. However, these studies introduced an acute, high intensity noise stressor to measure short-term changes in vigilance and, therefore, provide limited insight to how chronic ambient noise influences the daily lives of freeliving birds. Furthermore, to our knowledge, there are no previous studies that have examined how hypervigilance exhibited in captive birds translates to detection of and response to approaching threats in nature. Thus, we sought to test whether study of bird FIDs can provide evidence to clarify the contradicting hypotheses of distraction and hypervigilance. Furthermore, we sought to examine FID responses in light of the different avian feeding ecologies that have the potential to influence detection of approaching threats via auditory and visual surveillance.

Here, we categorize our study species into three foraging guilds based on foraging behavior: ground foragers, canopy gleaners, and hawking flycatchers. We then use existing literature on the sensory ecology linked to each foraging strategy to formulate predictions of how ambient noise might influence FIDs for our foraging guilds. Most birds rely on vision for both foraging and vigilance and can maintain vigilance while searching for food through peripheral vision and frequent movement of the head and eyes to maximize the visual field (Lima and Bednekoff 1999; Fernández et al. 2008). These behaviors, as well as adapted visual fields, are thought to be primarily determined by feeding ecology (Martin 2007). Ground foraging birds generally have wide lateral visual fields and engage in frequent head movements to compensate for time spent headdown looking for food (Fernández-Juricic et al. 2008; Fernández-Juricic et al. 2011). 
Thus, we hypothesize that ground foraging species rely heavily on acoustic cues for threat detection while foraging and predict that they are more susceptible to the effects of masking in noisy conditions and will demonstrate decreasing FIDs as noise increases (Figure 1).

To our knowledge, no previous study has specifically investigated the sensory ecology of species that glean arthropods and fruit in the canopy. However, like the ground foragers, canopy gleaners also rely heavily on vision to both forage and scan for predators. Yet, because these species often forage high in the canopy rather than on the ground, we predict either a weak negative influence of noise or no change in FID in response to humans approaching at the ground level (Figure 1).

In contrast, flycatching species that sally out from a perch to catch flying insects on the wing visually scan for prey. Gall and Fernández-Juricic (2010) determined that the vision of the flycatching black phoebe (Sayornis nigricans) is primed for tracking active prey in three dimensions, but, to our knowledge, no studies have examined audition of any flycatching species in the context of foraging. With their constant visual vigilance for seeking prey, we hypothesize that these species may also able to detect approaching threats as an epiphenomenon of scanning for volant prey. Based on this foraging strategy and the FEAR hypothesis (Samia and Blumstein 2015), we predict flycatching species exhibit unchanged FIDs because they would flush upon first visual detection of an approaching threat while visually scanning for prey regardless of noise level (Figure 1). Alternatively, if flycatching species also compensate for reduced auditory surveillance for threats with increased visual vigilance, FIDs may increase with noise levels because more frequent visual scans for threats would lead to earlier detections (Figure 1). It is 
important to note that our expectation of varied responses for different foraging guilds is speculative due to limited literature on the visual fields and sensory ecology of species outside the ground foraging guild. However, we ultimately focus on the implications of ambient noise altering avian behavior in the context of human-wildlife interactions. Importantly, changes in FID for common songbird species in response to noise might influence how close human observers can approach wild birds, and thus, alter the quality of an experience with wildlife and nature.

\subsection{MATERIALS AND METHODS}

\subsubsection{Data collection}

We studied avian FIDs in relationship to background noise in urban parks and protected natural spaces throughout San Luis Obispo County, Muir Woods National Monument, California, and Grand Teton National Park, Wyoming. Our sites represented a range of background sound levels to capture natural variation in ambient noise and we did not manipulate the acoustic environment during our observations. Following previously described methods (e.g. Blumstein et al. 2003), a single observer located an individual bird and recorded the species, time, and initial distance between the observer and the target bird (Starting Distance) using an optical range finder (Nikon Aculon, Nikon Vision Co., Japan; TruPulse 360 R, Laser Technology, Inc., Colorado, USA). We targeted birds that were foraging, preening, or otherwise undisturbed by the intruder at the starting distance and not interacting with con- or hetero-specifics. While looking directly at the bird, the observer walked at a standard rate of $0.5 \mathrm{~m} / \mathrm{s}$ along a straight path toward the target bird and dropped a marker at the distance where the bird flew away from the 
intruder (Flight Initiation Distance, measured as the distance between this marker and the bird's last perch). Immediately following the bird's escape, the observer measured timeaveraged sound levels (Leq; A-weighted Leq, fast response, re. $20 \mu \mathrm{Pa}$ ) for at least one minute at the bird's last perch with a Larson Davis 824 or 831 sound pressure meter or a MicWi436 (MicW Audio, China) microphone paired with the SPLnFFT Sound Meter v6.2 iPhone application (FL's Audio Apps, France), a measurement kit equivalent to a type two sound level meter (Kardous and Shaw 2014). We also measured wind speed with a Kestrel 4000 weather meter (Kestrel Meters, USA). During the sound pressure level measurement, the observer scanned the surroundings and counted any pedestrians and their distances to the bird's last perch. We utilized pedestrian activity, previous knowledge of site location, and proximity to roadways to categorize each site as either a predominantly developed or natural area. Sound levels, which were primarily from anthropogenic sources, such as roadways, did not systematically differ between developed (49.35 $\pm 4.70 \mathrm{SD} \mathrm{dB}(\mathrm{A}))$ and natural areas (50.26 $\pm 9.55 \mathrm{SD} \mathrm{dB}(\mathrm{A})$; Welch's two sample $t$-test, $t=0.87, \mathrm{df}=155.66, p>0.38)$. The observer then used a surveyor's tape or laser range finder to measure the FID, the distance between the bird's last perch to the dropped marker. If the bird was perched above the ground, we measured the Euclidean distance as the square root of the sum of the squared horizontal distance and squared perch height (Møller et al. 2015). Finally, the observer categorized surrounding vegetation as open, medium, or dense. To avoid sampling the same individual more than once, the observer moved at least 250 meters from the first survey before locating a subsequent individual. We also visited sites throughout each location only once to avoid resampling individuals. 


\subsubsection{Data analysis}

We used a $\log _{10}$ transformation on all distance data to normalize their distributions. We assigned each of the surveyed species to one of three foraging guilds based on foraging behavior: ground foragers, canopy gleaners, and hawking flycatchers (Ehrlich, Dobkin and Wheye 1988). Because we were most interested in the influence of noise on FIDs, using the entire dataset we first calculated adjusted FIDs as the residuals of a linear regression model where raw FIDs were explained by vegetation category and starting distance, two variables known to strongly influence FID (e.g. Blumstein 2003, Blumstein et al. 2005, Fernández-Juricic et al. 2002). We then used linear mixed effect models using the lme4 package (Bates et al. 2012) in $\mathrm{R}$ with vegetation and starting distance-corrected FID (henceforth adjusted FID) for each foraging guild as a response variable and background sound level, wind speed, Julian date, time of day, developed versus natural habitat, species and an interaction between sound level and species as fixed effects. Models for canopy gleaners did not include developed versus natural habitat because all individuals were sampled in areas categorized as natural. In all models, we also treated location as a random intercept. We used Akaike information criterion corrected for small sample size $\left(\mathrm{AIC}_{c}\right)$ in model selection. Because of recent criticisms of model-averaging (Cade 2015), we considered all models with $\Delta \mathrm{AIC}_{c}<2$ to be equivalent (Boersma et al. 2016). To gauge the influence of individual predictors, for each model with $\Delta \mathrm{AIC}_{c}<2$, we concluded that a predictor variable had a strong effect on adjusted FID when its $95 \%$ confidence interval (95\% CIs) did not overlap zero.

Finally, foraging guilds may also reflect shared evolutionary histories that could influence variation in FID values among guilds. For example, all species categorized as hawking flycatchers are suboscines in family Tyrannidae. Thus, we tested for 
phylogenetic structure in mean FID values among species and species-specific modelestimated effect sizes for the influence of background sound levels on adjusted FIDs, including standard errors, using the phylosig function in the R package phytools (Revell 2012), which incorporates the method from Ives et al. (2007) to account for sampling error. For our phylogenetic hypotheses, we used phylogenies from Jetz et al. (2012) and available from Birdtree.org. However, due to phylogenetic uncertainty among the Jetz et al. set, we used 100 randomly selected trees to calculate mean values for two common metrics for phylogenetic signal: Pagel's $\lambda$ (Pagel 1999) and Blomberg's K (Blomberg et al. 2003). Pagel's $\lambda$ values vary from zero to one. High $\lambda$ values indicate that closely related species have very similar trait values (i.e., high phylogentic structure). Low $\lambda$ values indicate that trait values are unrelated to phylogeny. Blomberg's K values $>1$ suggest strong phylogenetic signal and values from zero to 1 suggest no phylogenetic signal to weak phylogenetic signal.

\subsection{RESULTS}

\subsubsection{Summary}

We surveyed a total of 197 individuals of 12 species of songbird across 27 locations from January to July 2016. Due to wind speed exceeding Category 3 on the Beaufort scale, we excluded one observation from the dataset to prevent potential bias introduced to sound measurements (Francis et al. 2011). Of the resulting 196 individuals, 105 were ground foragers, 52 canopy gleaners, and 39 flycatchers (Table 1). These individuals were sampled across 46 developed and 150 natural sites. We conducted trials throughout the day (0600 to 1630); however, we conducted most our observations (179 of 196) between 
0600 and 1200 hours. Wind speed ranged from $0 \mathrm{~m} / \mathrm{s}$ to $5.5 \mathrm{~m} / \mathrm{s}$, with an average of 0.68 $\pm 0.93 \mathrm{~m} / \mathrm{s}$. Background sound levels ranged from 17.0 to $77.4 \mathrm{~dB}(\mathrm{~A})$ with an average of $50.04 \pm 8.68 \mathrm{~dB}(\mathrm{~A})$. Starting and flight initiation distances averaged $26.76 \pm 15.01 \mathrm{~m}$ and $10.77 \pm 7.32 \mathrm{~m}$, respectively. We found no evidence for phylogenetic structure for mean FID (Pagel's $\lambda=0.01, \mathrm{sd}=0.1$; Blomberg's $\mathrm{K}=0.41, \mathrm{sd}=0.03$ ), but evidence for a weak to moderate phylogenetic signal for the effect of noise on adjusted FID (Pagel's $\lambda=$ 0.50, sd =0.30; Blomberg's $\mathrm{K}=0.77, \mathrm{sd}=0.07$ ).

\subsubsection{Foraging guilds}

Among the top models for ground foraging species, the parameters background noise, diet, and species had strong effects, where $95 \%$ confidence intervals did not overlap zero (Table 2). The model that only included the random effect of location (i.e., null) was 2.00 $\Delta \mathrm{AIC}_{c}$ from the top model. We visualized our results using the most parsimonious top model, which demonstrates an overall negative influence of background noise level on FIDs for all ground foraging species (Figure 2B). However, several ground foraging species differed in their overall response distances (i.e., different intercepts per species (Figure 2A; Table 3). Our results indicate that the individuals from the ground foraging guild were generally slower to respond to an observer's approach with elevated background sound and that omnivorous species flush at farther distances than granivorous species.

Among the top models for canopy gleaning species, the parameters with strong effects, included background noise, species, and an interaction between the two (Table 2). The null model (location as random intercept only) was $38.42 \Delta \mathrm{AIC}_{c}$ lower than the top model. Wilson's warbler (Cardellina pusilla) adjusted FIDs were positively influenced 
by background noise, Pacific wren (Troglodytes pacificus) adjusted FIDs were negatively affected by noise and yellow warblers (Setophaga petechia) appear uninfluenced by noise (Figure 2C-E; Table 4).

In the flycatching guild, the best model contained species, background noise, and an interaction between the two as fixed effects (Table 2). It was $29.6 \Delta \mathrm{AIC}_{c}$ better than the null model that only included the random effect of location and there were no other

models with $\Delta \mathrm{AIC}_{c}<2$. Background noise levels had a strong positive influence on black phoebe (Sayornis nigricans) adjusted FIDs (Figure 2F), but adjusted FIDs for both the Pacific-slope flycatcher (Empidonax difficilis) and dusky flycatcher (Empidonax oberholseri) were negatively affected by noise, albeit weakly (Figure 2G-H; Table 5).

\subsection{DISCUSSION}

To our knowledge, this report is the first to specifically address changes in songbird FIDs in response to noise, with implications for how noise influences predation risk and missed foraging opportunity as well as bird behavior relevant to casual nature-seekers and birdwatchers. Through our observations of wild songbird FIDs in varying acoustic conditions, we found evidence that noise influences bird FIDs in a variety of ways. We found no evidence that mean FID values were influenced by relatedness of species in our sample. However, the effect of noise on adjusted FIDs had some phylogenetic signal, likely reflecting that model estimates found identical relationships between noise and adjusted FID among all Emberizid species and because the congener flycatchers demonstrated similar adjusted FID responses with increasing noise. In general, however, our results indicate mixed responses across songbirds that can be species-specific and that 
might be explained in part by foraging behavior and, possibly, height of perch in the canopy.

All species within the ground foraging guild exhibited shorter FIDs in noise, as we predicted, such that the observer could approach closer to the target bird before it flushed. Shorter FID responses in noisy conditions may be explained by the distracted prey hypothesis, which posits that background noise occupies the target bird's finite attention and thus distracts the individual from other potentially important stimuli (Chan et al. 2010). Although the distracted prey hypothesis may explain shortened FIDs in noise for some of these bird species, it is impossible to uncouple distraction from the effects of energetic masking. The high background sound in some areas might have masked the sounds of an approaching observer, leading to a slower response from the target bird. Of course, both mechanisms could operate simultaneously. Regardless, the result is that noise reduces an individual's ability to detect approaching threats and likely elevates an individual's risk of predation (Krause and Godin 1996; Simpson et al. 2016); failure to detect predators at a sufficient distance could be lethal.

Although our results suggest ground foraging birds may be more at risk to predation in noisy environments, the effects of masking and noise on predator abundance and hunting ability must also be considered. Opportunistic avian nest predators avoid noisy areas in a natural gas extraction field (Francis et al. 2009; 2012) and owls, which are specialized acoustic predators, have trouble localizing or foraging in noisy conditions found in gas fields and near roadways (Mason et al. 2016; Senzaki et al. 2016). In laboratory settings, both Quinn et al. (2006) and Ware et al. (2015) demonstrated that ground foraging species spend significantly more time visually scanning for predators 
when ambient noise is high compared to quiet conditions. If ground foraging birds in our study also increase visual vigilance with noise, our results suggest that they were still unable to detect and respond to approaching threats as quickly as in quiet conditions, despite compensating with visual scans. Notwithstanding the potential ultimate costs of failing to detect predators at an appropriate distance, for human observers seeking to experience wild birds at close range, species that flee at shorter distances in noisy conditions would be easier to approach, view and hear. Finally, diet was also a significant predictor of FID for ground foraging species; species with omnivorous diets exhibited longer FIDs than species with granivorous diets irrespective of noise levels. Although limited evidence can help explain this trend, Francis (2015) demonstrated that the abundance of most avian species decline in noisy areas, species with plant-based diets appear to be less sensitive than those with animal-based diets. It is also possible that other traits unique to the two omnivorous species, which are both corvids, could explain their longer FIDs relative to granivorous species. For example, various measurements of brain size are positively associated with FIDs (Symonds et al. 2016) and corvids are known to have relatively large brains (Emery and Clayton 2004). Greater cognitive capacity could also potentially mitigate distraction by noise and other stimuli (i.e., distracted prey hypothesis) by permitting individuals to process multiple streams of sensory information and respond to approaching threats appropriately. Future work should explore the relative contributions of cognitive abilities and foraging modalities to explain FIDs or sensitivities to changes in background acoustics in general.

For the canopy gleaning guild, we predicted that FIDs would decrease as a result of distraction or masking due to increased ambient noise. However, we suspected that 
because these species often utilize high tree perches, they might only exhibit weakly decreased or unchanged FIDs to a human approaching on the ground due to vertical relief from the threat. Although these predictions were not supported for all canopy gleaning species, we observed a trend of decreased FIDs with increasing noise for Pacific wrens (Troglodytes pacificus) and a pattern of unchanged FIDs for yellow warblers (Setophaga petechia). Similar to the ground foraging species, Pacific wrens may be more susceptible to the effects of masking or distraction due to frequent sensory modality shifts as they remain acoustically vigilant while visually foraging. Pacific wrens are known to forage in the low canopy and, thus, experience little vertical relief from ground-level threats; however, yellow warblers frequently utilize high perches, which may explain the lack of FID response for the species. Additionally, although our robust sampling of yellow warblers indicates that this species exhibits consistent FID behavior across medium to high sound levels (46.9-77.4 $\mathrm{dB}(\mathrm{A})$ ), we were unable to conduct any approaches under relatively low ambient sound conditions $(<40 \mathrm{~dB}(\mathrm{~A}))$. Future work should focus on observing yellow warblers in environments with less ambient noise, as even acoustic cues at these relatively quiet levels can elicit responses in other taxa (Shannon et al. 2015) and perhaps there is a threshold below which noise might influence FID in yellow warblers. In contrast to our predictions for the canopy gleaning guild, Wilson's warblers (Cardellina pusilla) exhibited a trend of increased FIDs with increasing noise. Wilson's warblers primarily forage by gleaning insects in the canopy, but they are also known to hawk for flying insect prey (Ehrlich, Dobkin and Wheye 1988) and, thus, might utilize sensory modalities differently when compared to other canopy gleaning species. However, yellow warblers are also occasional flycatchers (Ehrlich, Dobkin and Wheye 
1988) and, yet, do not exhibit the same increased FIDs of Wilson's warblers. Thus, engaging in flycatching behavior cannot solely explain the pattern consistent with hypervigilance in noise among Wilson's warblers. Finally, although two of the canopy gleaning species studied here fit our predictions of decreased FIDs or no response, future research should explicitly include individual perch height as a potential predictor of variation in FIDs both within and across species.

Our observed results for Wilson's warblers follow our prediction for species of the flycatching guild such that these species would exhibit unchanged or increased FIDs in noise due to their foraging strategy of constant visual and aural vigilance that might allow these species to scan for predators and prey simultaneously. However, only one species of the flycatching guild, the black phoebe (Sayornis nigricans), provided support for this prediction with increasing FIDs with increases in noise levels. The other two species of this guild, dusky flycatchers (Empidonax oberholseri) and Pacific-slope flycatchers (Empidonax difficilis), exhibited a weak trend of decreased FIDs with increasing noise. This muted response might be explained by our small sample size or perhaps like the canopy gleaning yellow warblers, by these flycatchers' shared tendency to utilize high perches, thereby relieving the threat of a ground-level approaching human. In the case of the black phoebe, however, our robust sampling in a wide range of ambient noise conditions indicates that this species is generally more likely to flush sooner if background noise is high. Such increased FIDs in noise might be explained by heightened vigilance in noisy conditions, which was demonstrated in laboratory settings with chaffinches (Quinn et al. 2006) and white-crowned sparrows (Ware et al. 2015) as well as in a field experiment with free-ranging prairie dogs (Shannon et al. 2016). Furthermore, 
flushing more quickly in noise coincides with the flush early and avoid the rush (FEAR) hypothesis, which suggests that birds are likely to flush quickly after detection in order to avoid the need to monitor an approaching threat (Blumstein 2010). This response might allow for more foraging time if the bird flushes to an area with available food; however, fleeing from a beneficial foraging site may result in lost foraging opportunity and could incur the cost of increased energy expenditure.

\subsection{CONCLUSION}

In the context of human experience of wildlife, our results indicate that background noise may influence the quality of a birdwatching experience. Due to their hawking behaviors, both Wilson's warblers and black phoebes can be exciting birds to observe.

Both species exhibited longer FIDs in noise, indicating that birdwatchers may experience difficulty when seeking these species and perhaps other hawking species in noisy conditions. However, most of the species in our sample trended toward shorter FIDs in noise, which would allow birders to approach closer. This may lead to a surprisingly positive outcome of anthropogenic noise pollution, under which birdwatching experiences are improved through field observations at closer range in noisier conditions. Particularly for new birdwatchers, this close viewing of wild birds may foster a personal and lasting connection with wildlife and lead to increased support for wildlife conservation. Of course, this potential benefit to nature-seekers of visually experiencing birds at a closer range must be viewed in the context of the quickly growing body of literature reporting the negative effects of noise and human disturbance to wild animals (Francis and Barber 2013; Ellison et al. 2012; Shannon et al. 2015). Nevertheless, our 
conclusions offer new perspective on the coexistence of humans and wildlife in an increasingly noisy world. 


\section{EFFECTS OF ANTHROPOGENIC NOISE ON AVIAN FEEDER COMMUNITY STRUCTURE AND FORAGING BEHAVIOR}

\subsection{INTRODUCTION}

Anthropogenic noise pollution impacts wildlife and humans in a variety of ways (Barber et al. 2010; Francis and Barber 2013; Shannon et al. 2016b; Francis et al. 2017). For wildlife, chronic exposure to noise degrades habitat quality and leads to decreased reproductive success and altered ecological interactions (Francis et al. 2009; Halfwerk et al. 2011; Kight et al. 2012; McClure et al. 2013; Ware et al. 2015). Many animals tend to avoid noise altogether (Bayne et al. 2008; McClure et al. 2013; Francis 2015). For humans, noise pollution is linked with increased hypertension and risk of cardiovascular disease (van Kempen and Babisch 2012), compromised learning in children (Stansfeld et al. 2005) and reduced health benefits, such as stress reduction and cognitive restoration, that people gain from interacting with nature (Francis et al. 2017). Unfortunately, noise pollution permeates landscapes well beyond the confines of urban centers. Recent estimates of elevated sound levels across the contiguous United States suggest that over $80 \%$ of the landscape is impacted by anthropogenic noise (Mennitt et al. 2013), including many national parks and other protected areas (Buxton et al. 2017). Given the near omnipresence of noise and documented negative effects on people and wildlife, there is a growing need to fully understand the consequences of noise exposure and how it shapes the lives of humans living in noise and the ecological systems surrounding them.

The primary way in which anthropogenic noise changes the environment is by interfering with biologically relevant sounds through a process called masking (Barber et al. 2010). Many wild animals communicate through acoustic cues and rely upon natural 
sounds like wind and moving water to gather information about their surroundings, leading to challenges when those natural cues are masked by anthropogenic noise (reviewed in Francis et al. 2017). Acoustic environments dominated by natural sounds provide psychological and physical benefits to humans as well. Birdsong, in particular, is known to relieve stress and improve cognitive restoration (Ratcliffe et al. 2013; Abbott et al. 2016). Keepers of bird feeders self-report an increased sense of wellbeing as well as a stronger connection with nature through maintaining and experiencing the sights and sounds of birds at their feeders (Jones and Reynolds 2008). Across the United States, bird feeding is growing in popularity, with approximately $\$ 5$ million spent on feeders, bird seed, and other supplies annually (US Fish and Wildlife Service 2016). Bird feeding extends beyond recreation as well -- Cornell Lab of Ornithology's Project FeederWatch reports 22,082 citizen scientists contributed to their database in 2016 . These data support the idea that birds are an important link to the natural world for many humans, in part due to the emotional and psychological benefits we gain from interacting with them.

Previous research suggests that anthropogenic noise can influence the community structure of breeding birds (e.g., Bayne et al. 2008; Francis et al. 2009; Proppe et al. 2013). However, the majority of this research was conducted during the breeding season, and yet effects of noise may be quite context-dependent (Ellison et al. 2012; Francis and Barber 2013). Sensitivities in one circumstance, such as when attracting mates or rearing young, may not translate into sensitivities in other situations, such as for predator detection, foraging, or orientation. Thus, it remains an open question as to whether noise influences birds outside the context of the breeding season, such as during winter feeder use. Still, two laboratory-based studies suggest that noise exposure could influence 
foraging and scale up to affect species abundance and feeder community structure. Quinn et al. (2006) found that captive-bred chaffinches (Fringilla coelebs) spent more time in a vigilant posture and less time foraging during playbacks of white noise, purportedly due to interference of the noise with auditory surveillance while the birds experienced limited vision as they foraged. Ware et al. (2015) confirmed these findings with captured whitecrowned sparrows (Zonotrichia leucophrys) exposed to playbacks of road noise in a laboratory setting.

Here, we assessed activity of 17 avian species at four feeders spread across a small area and tested whether feeder activity by individual species and the community as a whole changes under different experimental acoustic conditions. Because exposure to noise can interfere with the detection of acoustic cues and alter a variety of behaviors, we hypothesized that local birds would preferentially avoid feeders exposed to playback of traffic noise and use nearby feeders with quieter conditions. We predicted that overall abundance and species richness would decline with elevated background sound levels. We also expected the structure of avian communities to differ at feeders between noise and quiet intervals and that community turnover (i.e., beta diversity) would be explained by overall sound levels. Additionally, to determine whether the impact of noise on foraging and vigilance documented in laboratory studies translates to wild birds in a natural setting where other possible responses are available to them (e.g., leaving noisy areas, changes in social interactions and group size), we quantified foraging-vigilance trade-off in two abundant species at our sites: white-crowned sparrows and dark-eyed juncos (Junco hyemalis). We predicted that individuals exposed to increases in background sound levels would spend less time foraging and more time being vigilant. 


\subsection{MATERIALS AND METHODS}

\subsubsection{Site description}

Our study took place at Camp KEEP Ocean, an outdoor education camp, located in Montaña de Oro State Park on the Central Coast of California, US in December 2015 and January 2016 when the camp was empty for the holiday break. Across four established feeder locations (Figure 1), we maintained a tube feeder filled with thistle seed and a chalet-style feeder filled with a mix of sunflower, safflower, and millet seeds (Wild Birds Unlimited Deluxe Blend). All feeders were placed 1.5-2 $\mathrm{m}$ above ground and filled every morning to so that feeders were never depleted of seeds during the experiment. The four feeder sites were in slightly different habitats and experienced different levels of daily activity. Site A, located behind a staff trailer and against a eucalyptus grove, was protected from student access during program days, but closest to the road and ocean. Site B, placed in a manicured native plant garden bordered by the camp driveway and the deck of the cafeteria, was most exposed to any pedestrian or vehicle access into the camp and offered a single tree and a few shrubs as refuges for birds. Site C, backed by coastal scrub habitat, was most exposed to student access from the observation deck 7 meters away. Site D, placed 10 meters behind the student cabins against eucalyptus forest, was the least exposed to pedestrians and vehicle noise. The only road in the state park, located approximately $100 \mathrm{~m}$ from the campus, allowed vehicle noise to enter the campus at nominal levels (45 miles/hour speed limit).

\subsubsection{Traffic noise recordings}

We used recordings of traffic noise made with Roland R05 recorders 10-12 m from local highways between October 2014 and May 2015. At each feeder, we played an 
approximately 3-min traffic noise recording, which was looped continuously from 700 to 1700 hours (approx. sunrise to sunset, the active time for birds). We used each playback at a single site for a two-day interval and randomly selected a new track for each subsequent site and interval. All recordings included a 5-second fade-in and fade-out at the looping juncture to reduce the possibility of startling, a known response in animals when noise levels drop in or cut out abruptly (reviewed in Francis and Barber 2013). We also standardized recording amplitudes to the same peak power in Raven Pro 1.5 to control for acoustic events of especially high amplitude.

\subsubsection{Experimental setup}

During the experiment, we cyclically exposed feeder sites to traffic noise or ambient sounds for two-day blocks. On the first day, we randomized which two feeder sites would receive the treatment of broadcast traffic noise and then alternated exposure to the other two feeder sites during the next two-day interval, and so on. We also randomized and selected without replacement which recording of traffic noise would be used during each interval. To broadcast the traffic recording, we set up Block Rocker AM/FM iPA16 speakers (Ion Sound Experiences, Rhode Island; frequency response: 70-20,000 Hz) 3 meters from the feeders. Each morning before sunrise we gradually introduced the looped track until the maximum sound pressure reached $70 \mathrm{~dB}(\mathrm{~A})$ at the feeders as measured with a Larson-Davis 824 sound pressure meter (Larson-Davis, New York). We aimed the directional speakers directly at the feeders and away from neighboring sites to limit propagation of experimental noise. We housed the speakers in plastic containers to protect them from weather and left empty containers at the sites without noise treatment to standardize the placement of novel objects during quiet intervals. 
To capture feeder activity, we set up Covert HD 40 game cameras (Covert Scouting Cameras, Kentucky) on tripods $7 \mathrm{~m}$ from the feeders at each site to record 20 seconds of video every 30 minutes from 700 until 1700 hours. We synchronized the cameras across all four sites to minimize the possibility of birds traveling among feeder sites during the 20-sec video recordings; however, cameras differed slightly in their timekeeping, resulting in mean offset toward the end of the day of 1-min 48-sec.

To capture acoustic conditions at the sites, we installed Roland R05 (Roland, Los Angeles) acoustic recording units within custom windscreens at each feeder site. These units recorded for the duration of the video schedule each day. To process the resulting 300 hours of acoustic recordings, we utilized the custom programs AUDIO2NVSPL and Acoustic Monitoring Toolbox (Damon Joyce, National Park Service) to convert our files to hourly sound pressure level format and then to hourly LEQ values in A weighted decibels $(\mathrm{dB}(\mathrm{A}))$ to estimate the received sound levels at the feeders each hour throughout the day. We then averaged the hourly LEQ values such that we had a single long-term time-integrated sound level representing each site on each day, which was used for further analyses (see below).

\subsubsection{Video processing}

Following completion of the study, we counted individual birds per species in all video recordings. We then calculated total abundance (total number of individuals) and species richness of birds using feeders present in each of the videos. We also noted non-avian visitors to the feeders, such as Black-tailed deer (Odocoileus hemionus). Following modified methods of Lepage and Francis (2002), we used the single highest count per 
species in a single day as a metric of maximum daily abundance of that species at each feeder, which eliminates double-counting individual birds at a feeder in a given day.

\subsubsection{Foraging-vigilance trade-off}

Several approaches can be used to measure trade-offs between time spent foraging and time spent vigilant. In their laboratory studies, Quinn et al. (2006) and Ware et al. (2015) quantified the time an individual spent with its head up versus down. In the context of the current experiment with free-living birds, this method proved difficult to quantify because we were unable to standardize the angle of view to quantify an individual's posture due to changes in body orientation. Instead, we measured pecking rate, which, based on the dataset of Ware et al. (2015), is a metric that is highly correlated with vigilance rate, or number of head-lifts per second (Pearson's correlation; $r=0.8804, p<$ 0.001), and thus represents a robust measure of both foraging and vigilance effort.

To measure pecking rate, we focused on the two most abundant species, whitecrowned sparrow (hereafter sparrows) and dark-eyed junco (hereafter juncos). We randomly selected 100 videos with the target species present and only included videos containing at least one individual that remained within the video frame for the full 20second recording. We scored the resulting 42 sparrow and 42 junco videos by randomly selecting an individual and counting the total number of pecks per 20 seconds. We also recorded the group size throughout the video, a parameter known to influence foraging and vigilance (Roberts 1996). 


\subsubsection{Data analysis}

Using repeated measures ANOVA, we confirmed that sound levels differed between treatment and control conditions and we compared sound levels across feeder sites. From the avian count data, we removed three species that appeared only once or twice during the experiment. To determine whether the presence or amplitude of traffic noise influenced turnover in community structure (i.e., beta diversity), we used PERMANOVA with the adonis function in the vegan 2.3 package in $\mathrm{R}$ (Oksanen et al. 2008). We also included feeder site and experimental interval, given the possibility that birds could potentially habituate to the noise stimulus over time and, thus, influence patterns in beta diversity. We used Bray-Curtis dissimilarity index to represent community turnover as it helps reveal underlying ecological gradients (Faith et al. 1987), such as those created by different sound levels. To visualize differences in avian communities across feeders, we created a 3-dimensional non-metric multidimensional scaling plot (3D NMDS) using the vegan3d package in $\mathrm{R}$ (Oksanen et al. 2017). We fit the ordination plot in four dimensions, which provided an excellent representation of the data in ordination space (stress $=0.084$ ). Finally, we plotted the effect of sound level on the NMDS axes using the envfit function in vegan.

To determine whether sound level influenced the activity of individual species, we used generalized linear mixed models (lme4 package in R; Bates et al. 2015). We treated scaled and centered (z-transformation) sound level as a fixed effect and site and interval as random effects. Site was included as a random effect to control for multiple observations made at a single location and interval was included as a random effect to capture potential temporal variation in activity levels due to weather or other factors. 
We were also interested in exploring whether activity level responses to noise were context-dependent on the abundance of heterospecific competitors and, therefore, effects of interspecific competition in these mixed flocks. We grouped species into one of two foraging guilds (ground or feeder-level foragers) and conducted the same generalized linear models with scaled summed activity for all other members of the foraging guild as a fixed effect and site and interval as random effects. For most generalized linear mixed effect models, we used Poisson distribution and checked model fit with dispersion tests (blmeco package in R; Korner-Nievergelt et al. 2015) and QQ plots. To correct for overdispersion in the model for mourning doves (Zenaida macroura), we added an observation-level random effect (Harrison 2015). We also removed site as a random effect in this model, as it explained next to zero $(<0.0001)$ variance in the model. To correct for underdispersion in our model for American crows (Corvus brachyrhynchos), we used a generalized linear mixed model with template model builder ( $g \operatorname{lmm} T M B$ package in R; Magnusson et al. 2017). We inferred that sound levels or treatment had a strong effect on species activity when the $95 \%$ confidence interval $(95 \% \mathrm{CI})$ did not overlap zero.

\subsubsection{Phylogenetic signal}

We tested for evolutionary relationships within sound level effects on species-specific daily activity using the R package phytools (Revell 2012), which accounts for sampling error using methods from Ives et al. (2007). In these analyses, we used coefficient estimates and their standard error from species-specific models described above as the traits and sampling error for the analysis. We used 100 randomly selected phylogenies 
from Birdtree.org to calculate mean values for Pagel's $\lambda$ (Pagel 1999) and Blomberg's K (Blomberg et al. 2003).

\subsubsection{Foraging-vigilance trade-off}

To assess the influence of background sound on pecking rate for our two target species (sparrows and juncos), we used linear mixed effect models with $\log _{10}$-transformed pecking rate as the response variable and scaled sound levels, scaled total activity, time of day, treatment type, as fixed effects with feeder site and interval as random effects. For example, increases in biotic sounds could reflect safe foraging conditions (reviewed in Francis et al. 2017).

For all models, we used Akaike information criterion corrected for small sample size $\left(\mathrm{AIC}_{c}\right)$ in model selection. We considered all models with $\Delta \mathrm{AIC}_{c}<2$ to be equivalent. When random effects explained little to no variance $(\mathrm{p}<0.0001)$, we removed them and refit the models as multiple linear regression (Bates et al. 2015) and inspected model fit via QQ plots. For our resulting models, we concluded that a predictor variable had a strong effect on pecking rate when its confidence interval (95\% CI) did not

overlap zero. We report effect sizes and 95\% CIs from the highest ranked model in which a parameter occurred and had a strong effect.

\subsection{RESULTS}

\subsubsection{Summary}

Over the course of 20 days, we collected 1,445 videos; however, equipment failures resulted in 10 days on which data at one or more feeder sites were unusable. We only 
included balanced days with an equal number of video observations at all four feeder sites. Our resulting dataset includes 824 video observations of feeder activity across 10 days. We observed a total of 17 avian and 1 non-avian species foraging at the feeders. Total activity across feeder sites varied, with average individuals per video as follows: $1.78 \pm 0.61 \mathrm{SD}$ at site $\mathrm{A}, 0.68 \pm 0.41$ at site $\mathrm{B}, 2.15 \pm 0.37$ at site $\mathrm{C}$, and $0.61 \pm 0.48$ at site D. The sound levels during treatment and ambient conditions were significantly different $\left(F_{1,23}=107.1, p<0.001 ;\right.$ Figure 4$)$, where noise exposure averaged $61.69 \pm$ $8.59 \mathrm{~dB}(\mathrm{~A})$ and ambient control conditions averaged $45.15 \pm 7.62 \mathrm{~dB}(\mathrm{~A})$. Additionally, sound levels differed significantly across feeder sites with Site $A$ as the loudest $\left(\mathrm{F}_{3,23}=\right.$ 23.76, $\mathrm{p}<0.001$; Figure 5).

\subsubsection{Community structure}

PERMANOVA results indicated a significant effect of sound level $\left(F_{1,22}=7.588, R^{2}=\right.$ $0.108, \mathrm{p}=0.001)$, site $\left(\mathrm{F}_{3,22}=7.746, \mathrm{R}^{2}=0.329, \mathrm{p}=0.001\right)$, interval $\left(\mathrm{F}_{5,22}=2.514, \mathrm{R}^{2}=\right.$ $0.178, p=0.001$ ) and a marginally non-significant effect of the presence or absence of noise $\left(F_{1,22}=2.150, R^{2}=0.030, p=0.074\right)$ on beta diversity across the feeder communities (Figure 6). For these data, daily mean sound levels ranged from 35.8 to 60.2 $\mathrm{dB}(\mathrm{A})$ and 50 to $75.4 \mathrm{~dB}(\mathrm{~A})$ under "quiet" and "noise" conditions, respectively.

\subsubsection{Daily activity}

Of the 14 species used in our analyses, three showed a significant effect of noise on their daily activity (Figure 7). Daily activity of mourning doves and Brewer's blackbirds increased with elevated sound levels (mourning dove $\beta \mathrm{SPL}=0.972,95 \%$ CIs 0.396, 1.595; Brewer's blackbird $\beta$ SPL $=1.803,95 \%$ CIs $0.891,3.329)$ and dark-eyed junco activity decreased with sound levels ( $\beta_{\mathrm{SPL}}=-0.189,95 \%$ CIs $\left.-0.343,-0.033\right)$. Furthermore, our 
model including all species also showed a positive influence of noise on total activity of all species $\left(\beta_{\mathrm{SPL}}=0.134,95 \%\right.$ CIs $\left.0.039,0.229\right)$. Our models that considered the abundance of heterospecific competitors had little influence on these patterns (Table 1A).

\subsubsection{Phylogenetic signal}

We detected a moderate level of phylogenetic signal on the relationship between sound level and species-specific daily activity from two different metrics (Pagel's $\lambda=0.47$, sd $=$ 0.30 ; Blomberg's $\mathrm{K}=0.87$, $\mathrm{sd}=0.01$ ), suggesting that the magnitude and direction of changes in activity level with respect to noise can be explained by relatedness.

\subsubsection{Foraging-vigilance trade-off}

Parameters within the top models $(\triangle \mathrm{AICc}<2.0)$ explaining junco pecking rate included sound level, treatment (experimental noise or ambient), and activity (total abundance of all individuals at feeder), plus the null model (Table 6). The included random effects interval and feeder site both explained little variance and were thus removed, making the model a multiple linear regression. However, none of the resulting parameters strongly explained variation in pecking rate for juncos (Table A2).

For sparrow pecking rate, estimated variance for feeder site and interval were near zero, thus we dropped random effects from the model and used multiple linear regression. The parameters of treatment, background sound level, time of day, and activity were included in models within 2.00 $\triangle \mathrm{AICc}$ (Table 7). Of these parameters, only sound level had a strong influence on pecking rate, exhibiting a negative relationship $\left(\beta_{\mathrm{SPL}}=-0.097\right.$, 95\% CIs -0.171, -0.022; Figure 8). 


\subsection{DISCUSSION}

\subsubsection{Summary}

We assessed bird behavior at four bird feeders spread across a small area and tested whether foraging activity changed under different acoustic conditions. Overall, our results indicated that sound levels did influence activity and community structure at bird feeders. We also observed reduced foraging time with increasing noise levels in whitecrowned sparrows, confirming in a natural setting what Ware et al. (2015) reported from controlled laboratory experiments. Though our field experiment had natural limitations, the trends we observed help demonstrate how wild birds are impacted by anthropogenic noise.

\subsubsection{Experimental design}

Given our focus on the interactions between humans and wild birds at feeders, we were most interested in bird activity and abundance patterns that a human observer could potentially witness. However, as with many field experiments, our design focused on free-living birds in their chosen habitats, which can come at the cost of experimental controls. Most importantly, individual birds were not uniquely marked and feeders were relatively close to one another. Thus, it is highly likely that the same individuals could visit multiple feeders within a day. To mitigate this complication, we utilized a common metric of daily maximum counts for each species (Lepage and Francis 2002) and repeated-measures analyses. Thus, our results provide an estimation of relative activity patterns with respect to noise exposure even when an unknown subset of individuals may be counted at one or more feeders per day. Finally, the four feeders were placed in locations with varying levels of anthropogenic influence and access. While this variation 
likely only represents a subset of the diverse conditions that birds at feeders experience in backyards across the globe, for this experiment the habitat differences added variability to our data, as illustrated by considerable turnover in the bird communities at each feeder in addition to noise exposure. These limitations aside, our experimental traffic noise exposure study suggests that noise can alter foraging behavior among free-living birds and also change activity patterns such that the overall composition of avian communities at feeders during noise exposure is different than under quiet conditions, even at the same location. We discuss these responses in greater detail below.

\subsubsection{Species activity levels and community turnover}

Cycles of experimental noise exposure altered the composition of the avian community at feeders to the degree that communities observed during noise treatments were significantly dissimilar from those during non-noise playback conditions. This change in the composition of the community occurs despite the fact that we did not see many species-specific changes in activity patterns. The three species that did have strong responses to background noise included mourning doves, Brewer's blackbirds (Euphagus cyanocephalus), and dark-eyed juncos. Both the mourning dove and Brewer's blackbird appeared to increase in abundance under increased sound levels. We also observed a slight positive influence of noise on total abundance when considering all species together, which could be due to species-specific habituation to noise levels. Brewer's blackbirds, for example, are frequently found in urban environments and may have a higher tolerance for anthropogenic noise (Martin 2002). However, mourning doves are more often found in less developed areas and nonetheless demonstrated increased activity in noise (Otis et al. 2008). This finding conflicts with that of Francis et al. (2009), in 
which mourning doves were found to strongly avoid noise-exposed areas in their nest placement. In a recent review, Ellison et al. (2012) suggested that animal responses to noise can only be understood only in light of the context: noise may impact animals only at particular life stages or when engaged in specific behaviors. It is possible that mourning doves exhibit noise-averse behaviors when breeding, but not at other times of the year. Additionally, it is also possible that increases in abundance of mourning doves with noise levels reflects a change in social behavior to cope with the foraging costs associated with noise exposure, i.e., group vigilance hypothesis (Roberts 1996). That is the per capita benefits to foraging rate by foraging in groups may counteract elevated vigilance due to noise exposure. However, we did not explicitly measure foraging rates or vigilance among mourning doves. In contrast to the blackbirds and doves, we observed decreased junco activity in noise conditions, indicating this species might be sensitive to noise. We also did not find any evidence that juncos alter pecking rate across different acoustic conditions, so perhaps this species less readily alters foraging behavior to compensate for the impact of noise on surveillance ability and instead tends to avoid noisy foraging sites.

Our evidence that activity patterns of most species appear unrelated to noise exposure stands in contrast to many other studies that have reported specific impacts of noise on certain species. For example, Woodhouse's scrubjays (Aphelocoma woodhouseii) [formerly known as the Western scrub-jay (Aphelocoma californica)] and spotted towhees (Pipilo maculatus) avoid noisy areas when breeding and hunting and alter territorial behaviors when exposed to noise (Francis et al. 2009; Kleist et al. 2015). However, some species appear to experience certain benefits from loud acoustic 
conditions. Previous work demonstrated that house finches (Haemorhous mexicanus) were more likely to place nests in noisy areas and even experienced improved nest success under loud conditions because of lower nest predation risk (Francis et al. 2009). When taken in light of our results, we might conclude that the context in which noise exposure occurs is vitally important. These previous studies focused on the breeding season, when avian diversity is generally at its peak in many areas, whereas we collected data in mid-winter when most birds are focused more on foraging and minimizing predation risk than maintaining territories, finding mates, or rearing young. The responses to noise that previous studies have reported among breeding birds does not preclude similar responses in other settings. One possibility is that wintering birds possess a different tolerance to noise pollution than breeding birds and future work should seek to understand whether responses to noise documented during breeding seasons match those of birds in non-breeding contexts.

To date, few studies have examined how the overall structure of a community changes in response to noise. Here, we report changes in abundance of a few species as well as the overall influence of sound amplitude in explaining the turnover in communities. Francis et al. (2009) found noise to reduce the richness of nesting bird communities by about $30 \%$ and that avian communities in quiet and loud areas were significantly dissimilar. Importantly, the communities in noisy areas were not merely subsets of the communities in quiet locations, primarily due to increases in abundance of some species in areas of noise (Francis et al. 2009). More recently, Bunkley et al. (2017) reported that the relative abundance of several arthropod families change with noise exposure, yet overall community structure did not differ between noise-exposed and quiet 
sites. While the study of noise pollution and its impact on wildlife is increasing, more research into community-level responses is needed to more fully understand the role of the acoustic environment in biological communities. One advantage of our study design is that we were able to use each feeder as its own control to study the feeder communities. By alternating time blocks of noise exposure, we show that, all else being equal, elevated sound levels can alter the composition of avian communities at feeders.

\subsubsection{Foraging rates}

Although two previous laboratory studies demonstrated that noise can influence foraging behavior in birds (Quinn et al. 2006; Ware et al. 2015), the question remained as to whether wild birds would demonstrate the same behavior or take advantage of other options. For example, rather than incurring the cost of foraging less while maintaining visual vigilance, wild birds may simply avoid noisy areas or alter coordinated group behavior to compensate for the effects of noise. Our results of foraging-vigilance tradeoff in wild, free-living white-crown sparrows further confirms the findings of Ware et al. (2015) that this species tends to spend less time foraging and more time visually scanning for predators if exposed to high background sound. Additionally, it is important to note that we did not find group size to be a significant predictor of this trade-off, a parameter known to influence vigilance behavior in mixed flocks (Roberts 1996). This phenomenon is not limited to birds, as Shannon et al. (2016a) demonstrated ground squirrels are hypervigilant in noisy conditions, spending less time foraging and engaging in social behaviors. Furthermore, this impact of noise on foraging behavior in many wild animals has implications for wildlife enthusiasts seeking encounters in potentially noisy areas (Petrelli et al. 2017). 


\subsection{CONCLUSION}

Ecological responses induced by noise exposure extend beyond that by wild organisms to also feedback on the type of experiences people have when enjoying nature, or wildlife as a subset of nature (Francis et al. 2017). North Americans are increasingly more interested in bird feeding as well as participating in citizen scientist feeder observations projects. Consideration of how noise might influence these valuable interactions for humans and wildlife are important for the future of these interests. Our results suggest that noise can alter avian communities at bird feeders, but the consequences of this trend on human experience with wildlife remains unknown. Ultimately, this study provides insight on another pathway through which anthropogenic noise is damaging the environment and interfering with humanity's connection with nature. 


\section{TABLES}

Table 1: We observed 196 individuals from 12 songbird species and grouped the species into three foraging guilds.

\begin{tabular}{lllr}
\hline Foraging Guild & Common name & Scientific name & Sample \\
& & & Size \\
\hline Ground & American Crow & Corvus brachyrhynchos & 12 \\
& California Scrub Jay & Aphelocoma californica & 13 \\
& California Towhee & Melozone crissalis & 12 \\
& Dark-eyed Junco & Junco hyemalis & 23 \\
& Golden-crowned Sparrow & Zonotrichia atricapilla & 7 \\
& White-crowned Sparrow & Zonotrichia leuchophrys & 38 \\
Canopy & & & \\
& Pacific Wren & Troglodytes pacificus & 12 \\
& Wilson's Warbler & Cardellina pusilla & 9 \\
& Yellow Warbler & Setophaga petechia & 31 \\
Flycatching & & & \\
& Black Phoebe & Sayornis nigricans & 19 \\
& Dusky Flycatcher & Empidonax oberholseri & 15 \\
& Pacific-slope Flycatcher & Empidonax difficilis & 5 \\
\hline Total & 12 species & & $\mathbf{1 9 6}$ \\
\hline
\end{tabular}


Table 2: Model selection table reports all the models within $2.00 \Delta \mathrm{AICc}$ in addition to the null model (intercept only) for each foraging guild. All models include location as a random effect. $\mathrm{K}$ indicates the number of parameters in the model. Model parameters include background sound level (dB), diet (e.g. omnivorous), habitat (either developed or natural), species, wind speed, and an interaction between background sound and species ( $\mathrm{dB} *$ Species). Bolded variable names indicate predictors with $95 \%$ confidence intervals that do not overlap zero.

\begin{tabular}{llccccc}
\hline $\begin{array}{l}\text { Foraging } \\
\text { Guild }\end{array}$ & Model & $\boldsymbol{K}$ & $\mathbf{d f}$ & $\mathbf{A I C} \boldsymbol{c}$ & $\begin{array}{c}\Delta \text { AIC } \\
\boldsymbol{c}\end{array}$ & weight \\
\hline Ground & & & & & & \\
& dB + Species & 3 & 9 & 10.6 & 0.00 & 0.139 \\
& dB + Diet + Species & 4 & 9 & 10.6 & 0.00 & 0.139 \\
& Diet & 2 & 4 & 10.9 & 0.31 & 0.119 \\
& dB + Diet & 3 & 5 & 11.4 & 0.77 & 0.095 \\
& dB + Habitat + Species & 4 & 10 & 11.8 & 1.25 & 0.075 \\
& dB + Diet + Habitat + Species & 5 & 10 & 11.8 & 1.25 & 0.075 \\
& Null (intercept only) & 1 & 3 & 12.6 & 2.00 & 0.051 \\
Canopy & dB + Species + dB*Species & 4 & 8 & -37.5 & 0.00 & 0.389 \\
& dB + Species + Wind speed + & 5 & 9 & -36.5 & 1.06 & 0.229 \\
& dB*Species & & & & & \\
& Null (intercept only) & 1 & 3 & 0.9 & 38.42 & 0.000 \\
\hline Flycatche & & & & & & \\
r & $\quad$ & 5 & 8 & -37.9 & 0.00 & 0.443 \\
& dB + Species + dB*Species & 1 & 3 & -29.6 & 8.28 & 0.007 \\
\hline
\end{tabular}


Table 3: The influence of fixed effects on adjusted FID for ground foraging species. Presented are effect sizes, standard error, 95\% confidence intervals from the top-ranking model (i.e. lowest AICc value and/or fewest parameters). The species included in this group are: American crow (Intercept), California towhee (CALT), dark-eyed junco (DEJU), golden-crowned sparrow (GCSP), white-crowned sparrow (WCSP), and California scrub jay (CASJ). Lower and upper confidence intervals represent $95 \%$ confidence. Bolded parameters have confidence intervals that do not overlap zero, indicating a strong effect.

\begin{tabular}{lcccc}
\hline \multicolumn{1}{c}{ Variable } & Estimate & Std. Error & Lower CI & Upper CI \\
\hline (Intercept) & 0.464 & 0.169 & 0.129 & 0.798 \\
dB & $\mathbf{- 0 . 0 0 7}$ & $\mathbf{0 . 0 0 3}$ & $\mathbf{- 0 . 0 1 3}$ & $\mathbf{- 0 . 0 0 0}$ \\
Species CALT & $\mathbf{- 0 . 2 9 2}$ & $\mathbf{0 . 0 9 5}$ & $\mathbf{- 0 . 4 7 9}$ & $\mathbf{- 0 . 1 0 4}$ \\
Species CASJ & $\mathbf{- 0 . 2 0 5}$ & $\mathbf{0 . 0 9 3}$ & $\mathbf{- 0 . 3 8 9}$ & $\mathbf{- 0 . 0 2 1}$ \\
Species DEJU & $\mathbf{- 0 . 2 9 1}$ & $\mathbf{0 . 0 8 3}$ & $\mathbf{- 0 . 4 5 6}$ & $\mathbf{- 0 . 1 2 6}$ \\
Species GCSP & $\mathbf{- 0 . 2 2 8}$ & $\mathbf{0 . 1 1 4}$ & $\mathbf{- 0 . 4 5 3}$ & $\mathbf{- 0 . 0 0 3}$ \\
Species WCSP & $\mathbf{- 0 . 1 5 3}$ & $\mathbf{0 . 0 7 7}$ & $\mathbf{- 0 . 3 0 5}$ & $\mathbf{- 0 . 0 0 1}$ \\
\hline
\end{tabular}


Table 4: The output for a linear mixed effect model of the canopy gleaning guild. The species included in this guild are: Pacific wren (Intercept), Wilson's warbler (WIWA), and yellow warbler (YEWA). The variables include background sound (dB), species, and interactions between background sound and species. Lower and upper confidence intervals represent $95 \%$ confidence. Bolded parameters have confidence intervals that do not overlap zero, indicating a strong effect.

\begin{tabular}{lcccc}
\hline Variable & Estimate & Std. Error & Lower CI & Upper CI \\
\hline (Intercept) & 1.064 & 0.303 & 0.459 & 1.669 \\
dB & $\mathbf{- 0 . 0 3 0}$ & $\mathbf{0 . 0 0 7}$ & $\mathbf{- 0 . 0 4 4}$ & $\mathbf{- 0 . 0 1 7}$ \\
Species WIWA & $\mathbf{- 4 . 2 2 5}$ & $\mathbf{0 . 7 4 6}$ & $\mathbf{- 5 . 7 1 3}$ & $\mathbf{- 2 . 7 3 6}$ \\
Species YEWA & -0.585 & 0.366 & -1.316 & 0.146 \\
dB*Species WIWA & $\mathbf{0 . 0 9 8}$ & $\mathbf{0 . 0 1 6}$ & $\mathbf{0 . 0 6 6}$ & $\mathbf{0 . 1 3 1}$ \\
dB*Species YEWA & $\mathbf{0 . 0 2 7}$ & $\mathbf{0 . 0 0 7}$ & $\mathbf{0 . 0 1 2}$ & $\mathbf{0 . 0 4 1}$ \\
\hline
\end{tabular}


Table 5: The output for a linear mixed effect model of the flycatching guild. The species included in this guild are: black phoebe (Intercept), dusky flycatcher (DUFL), and Pacific-slope flycatcher (PSFL). The variables include background sound (dB), species, and an interaction between the two. Lower and upper confidence intervals represent $95 \%$ confidence. Bolded parameters have confidence intervals that do not overlap zero, indicating a strong effect.

\begin{tabular}{lcccc}
\hline Variable & Estimate & Std. Error & Lower CI & Upper CI \\
\hline (Intercept) & -0.974 & 0.207 & -1.081 & -0.526 \\
dB & $\mathbf{0 . 0 1 9}$ & $\mathbf{0 . 0 0 4}$ & $\mathbf{0 . 0 1 8}$ & $\mathbf{0 . 0 2 1}$ \\
Species DUFL & $\mathbf{1 . 5 9 4}$ & $\mathbf{0 . 4 0 2}$ & $\mathbf{0 . 7 1 2}$ & $\mathbf{1 . 8 9 0}$ \\
Species PSFL & 1.149 & 0.366 & NA & 1.336 \\
dB $*$ Species DUFL & $\mathbf{- 0 . 0 2 6}$ & $\mathbf{0 . 0 0 7}$ & $\mathbf{- 0 . 0 3 1}$ & $\mathbf{- 0 . 0 1 2}$ \\
dB*Species PSFL & $\mathbf{- 0 . 0 2 5}$ & $\mathbf{0 . 0 0 8}$ & $\mathbf{- 0 . 0 2 8}$ & $\mathbf{- 0 . 0 1 2}$ \\
\hline
\end{tabular}


Table 6: This model selection table reports all the models for dark-eyed junco pecking rate within $2.00 \Delta$ AICc. All models include feeder site as a random effect. $\mathrm{K}$ indicates the number of parameters in the model. Model parameters include background sound level (dB), treatment (experimental noise or ambient), and activity (total abundance at feeder).

\begin{tabular}{|l|r|r|r|r|}
\hline Parameters & \multicolumn{1}{|l|}{ K } & \multicolumn{1}{c|}{ AIC $_{\boldsymbol{c}}$} & \multicolumn{1}{c|}{$\Delta \mathbf{A I C}_{\boldsymbol{c}}$} & \multicolumn{1}{c|}{ Weight } \\
\hline $\mathrm{dB}$ & 3 & -2.17 & 0.00 & 0.29 \\
\hline (Null) & 2 & -1.88 & 0.29 & 0.25 \\
\hline Tx & 3 & -1.48 & 0.69 & 0.20 \\
\hline Activity & 3 & -0.72 & 1.45 & 0.14 \\
\hline dB + Activity & 4 & -0.54 & 1.63 & 0.13 \\
\hline
\end{tabular}


Table 7: Model selection table reporting all the models for white-crowned sparrow pecking rate within 2.00 $\triangle \mathrm{AICc}$, plus the null. All models include feeder site as a random effect. $\mathrm{K}$ indicates the number of parameters in the model. Model parameters include background sound level (dB), time of day, treatment (experimental noise or ambient), and activity (total abundance at feeder). Parameters listed in bold had $95 \%$ CIs that did not overlap zero.

\begin{tabular}{|l|r|r|r|r|}
\hline Model & $\mathbf{K}$ & $\mathbf{A I C}_{\boldsymbol{c}}$ & $\Delta \mathbf{A I C}_{\boldsymbol{c}}$ & weight \\
\hline $\mathbf{d B}+$ Time & 4 & -0.95 & 0.00 & 0.15 \\
\hline $\mathbf{d B}+$ Time + Activity & 5 & -0.64 & 0.31 & 0.13 \\
\hline $\mathbf{d B}$ & 3 & -0.63 & 0.32 & 0.13 \\
\hline $\mathbf{d B}+$ Activity & 4 & -0.57 & 0.37 & 0.13 \\
\hline $\mathbf{d B}+$ Tx & 4 & -0.35 & 0.59 & 0.11 \\
\hline dB + Activity + Tx & 5 & -0.20 & 0.74 & 0.11 \\
\hline dB + Time + Tx & 5 & 0.05 & 1.00 & 0.09 \\
\hline dB + Time + Activity + Tx & 6 & 0.47 & 1.41 & 0.08 \\
\hline Activity & 3 & 0.68 & 1.62 & 0.07 \\
\hline Null & 2 & 2.51 & 3.46 & 0.00 \\
\hline
\end{tabular}




\section{FIGURES}

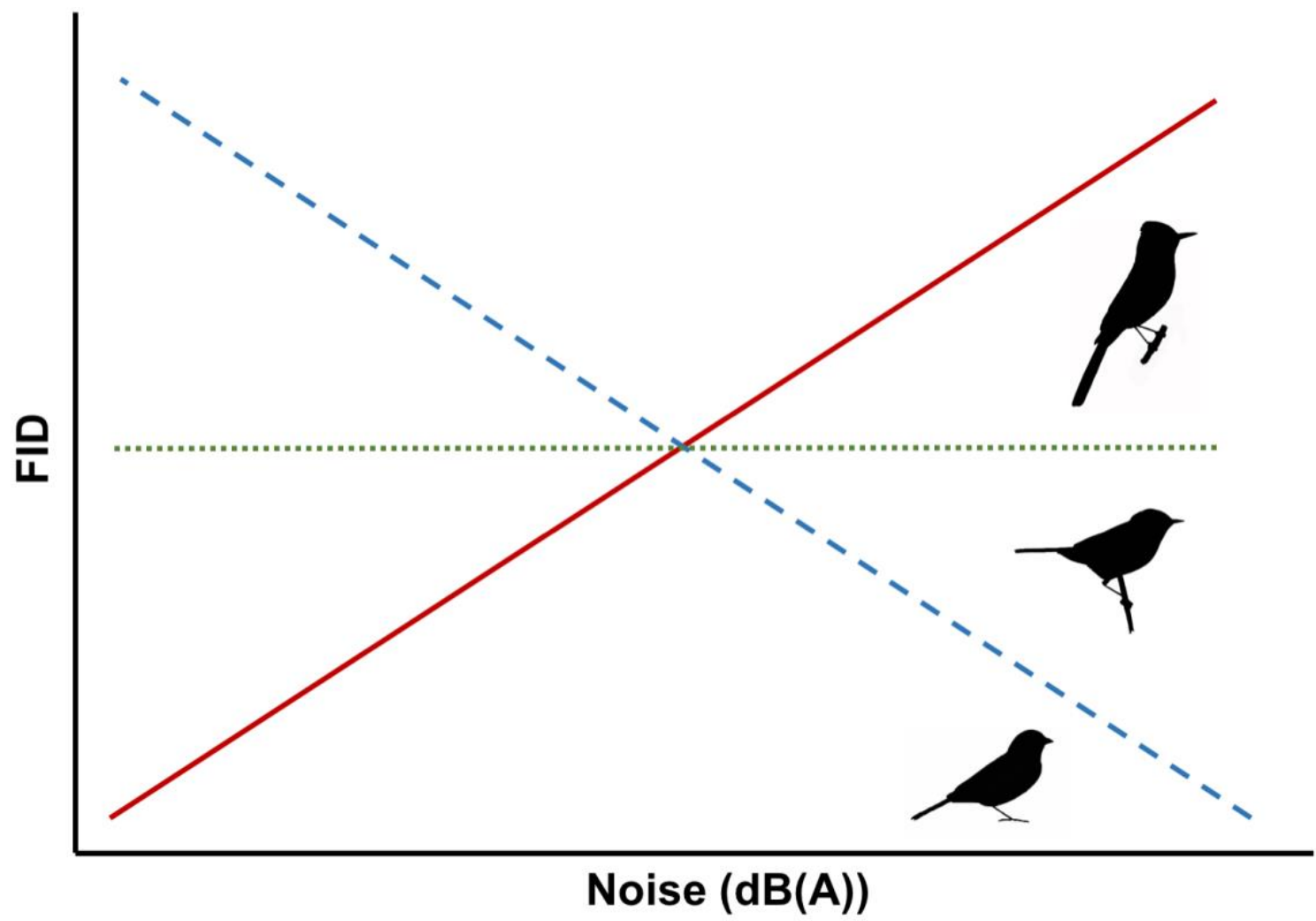

Figure 1: Predicted responses for three foraging guilds of songbirds. We expect ground foragers to have shorter FIDs in noise (dashed line), canopy gleaners to have shorter or unchanged FIDs (dashed or dotted lines), and flycatchers to have unchanged or longer FIDs in noise (dotted or solid lines). 

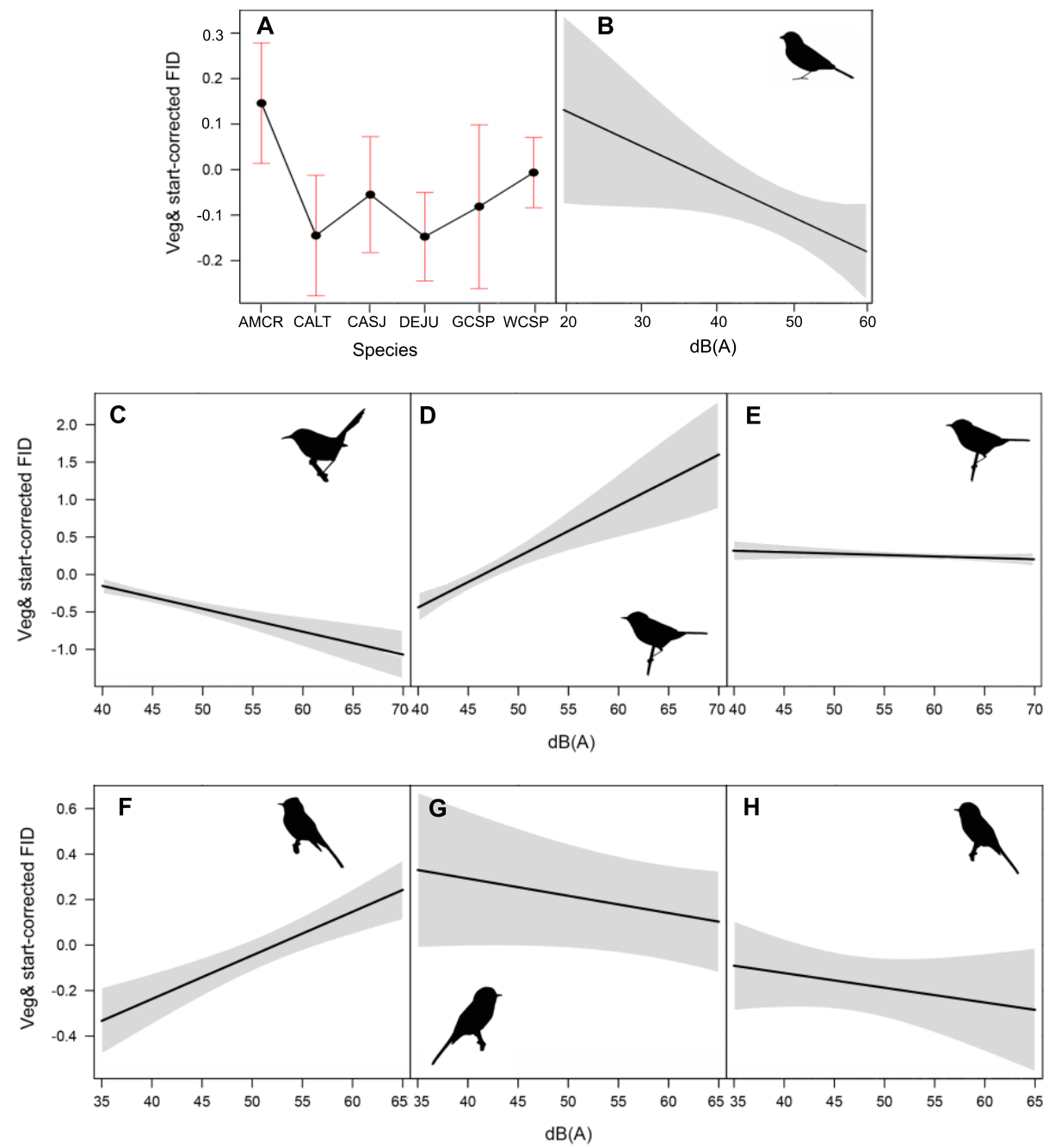

Figure 2: Panel A illustrates different intercepts to the slope depicted in panel $B$ for each species in the ground foraging guild. Different intercepts account for species-level differences in FIDs even though the effect of ambient noise on FIDs was indistinguishable for each (equal slope depicted in panel B). Species depicted are American crow (AMCR), California towhee (CALT), California scrub jay (CASJ), darkeyed junco (DEJU), golden-crowned sparrow (GCSP), and white-crowned sparrow (WCSP). Error bars represent 95\% confidence intervals for the estimated intercept for each species. Panels B-H illustrate the influence of ambient noise on vegetation and start distance-corrected FID values for all ground foraging species (B), canopy gleaning species Pacific wren (C), Wilson's warbler (D), yellow warbler (E), and flycatching species black phoebe $(F)$, dusky flycatcher $(\mathrm{G})$, and Pacific-slope flycatcher $(\mathrm{H})$. For plotting purposes, we utilized the top-ranking model (lowest AICc and fewest parameters) for each of the foraging guilds (Table 2). 


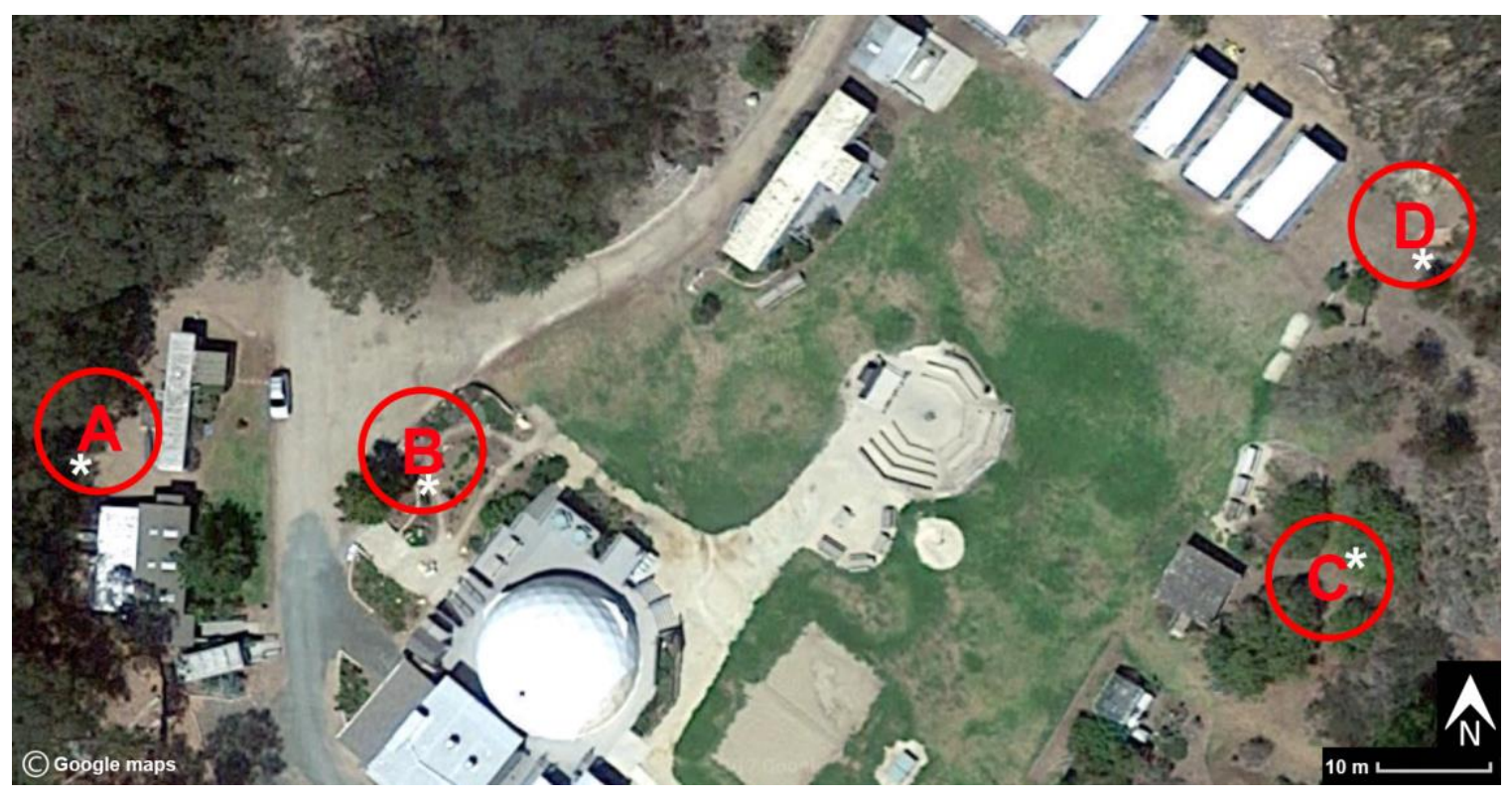

Figure 3: Satellite image of Camp KEEP campus, an area of approximately 1 hectare. Circled letters A-D indicate feeder locations used in our experiment and the white asterisks $(*)$ indicate relative speaker location. 


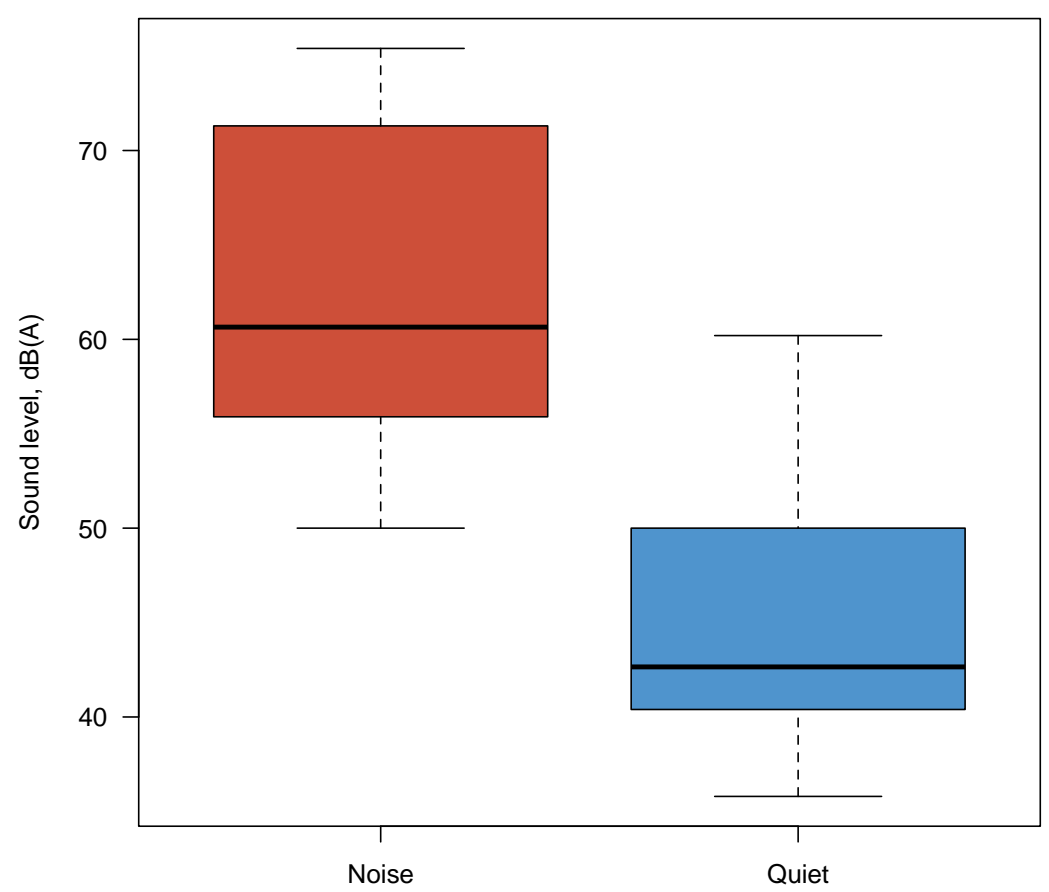

Figure 4: The daily average LEQ measurements during experimental noise exposure and ambient conditions differed significantly. 


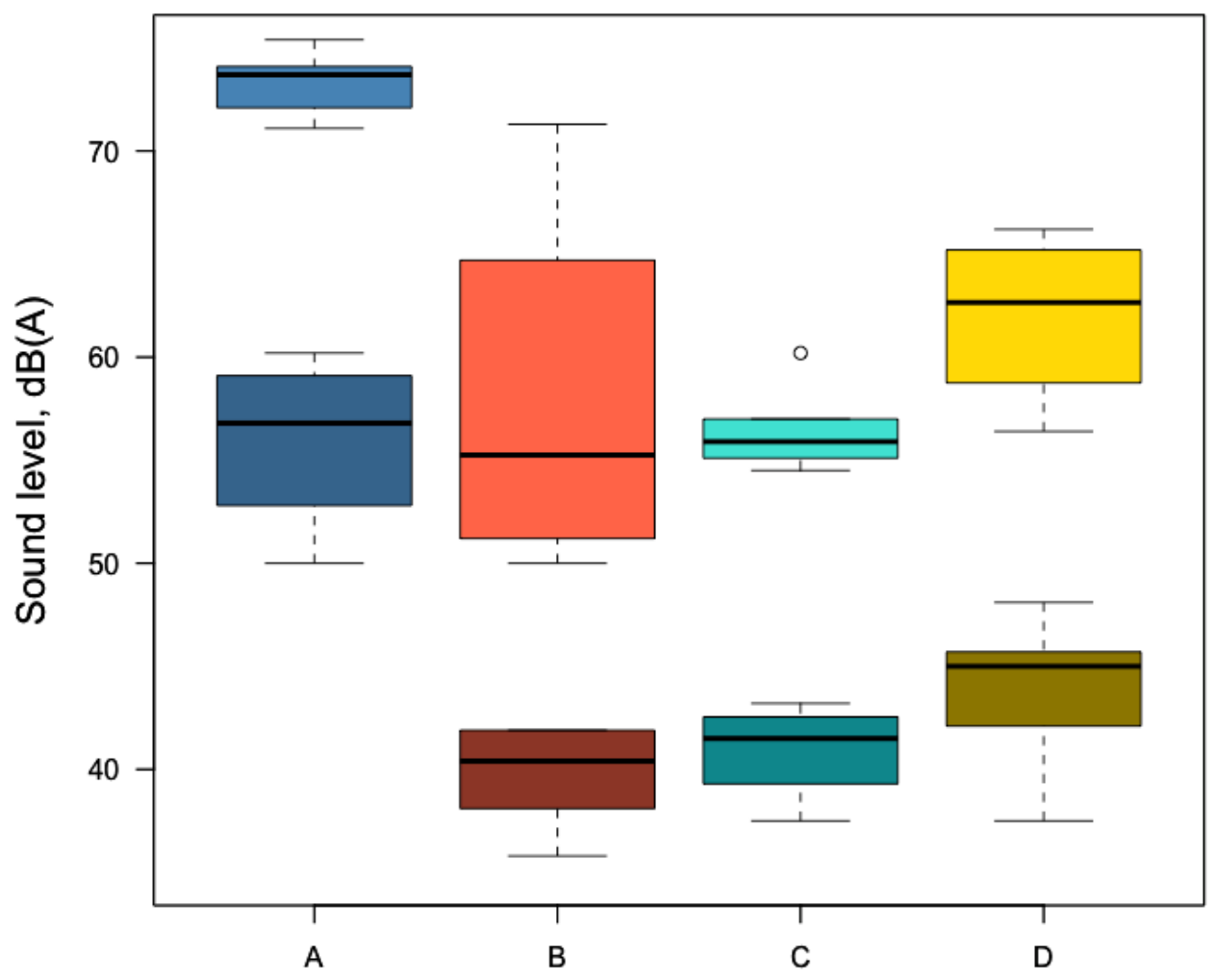

Figure 5: Average sound levels at the four feeder sites across the entire experiment differed significantly by treatment, with the noisiest conditions at Site A for quiet (lower darker boxes) and noise exposure (higher lighter boxes). 


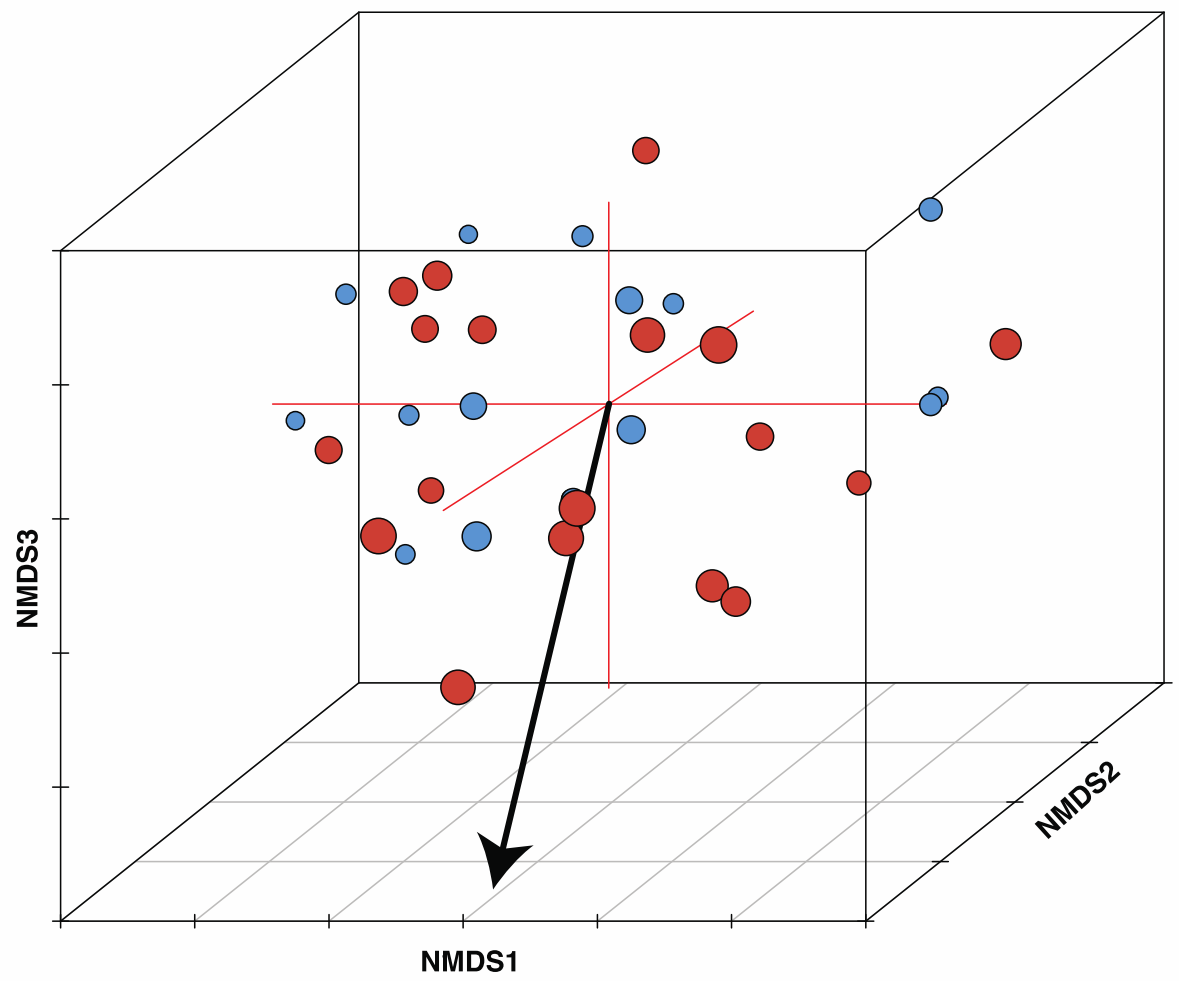

Figure 6: This three-dimensional nonmetric multidimensional scaling plot visualizes the avian communities of four different feeder sites. Colors indicate treatment (blue = quiet conditions, red = noise conditions) and the size of the points indicates scaled sound levels at the feeder. The arrow represents the relative influence of sound level on the NMDS axes. 


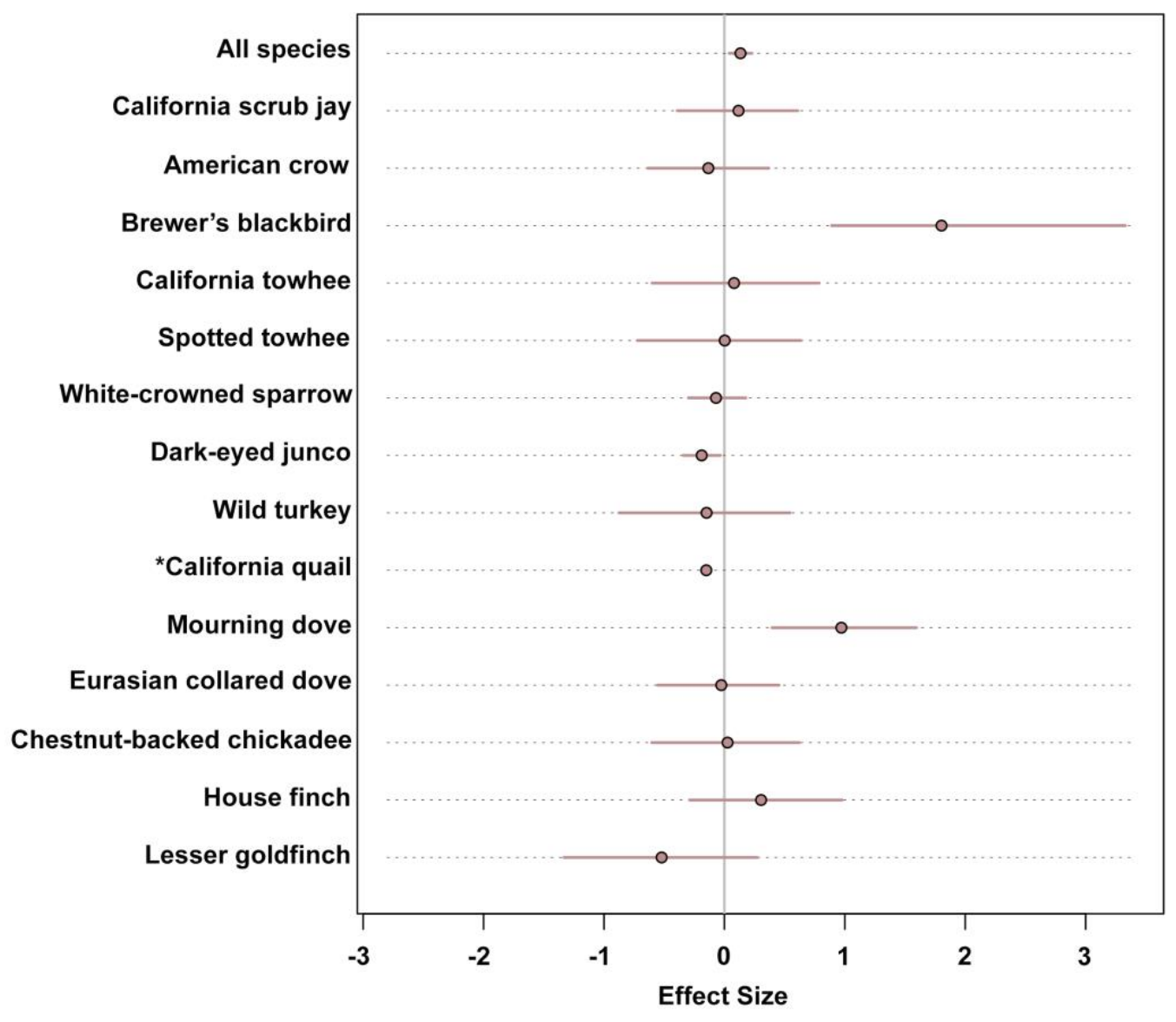

Figure 7: Value and direction of the effect of sound level on the daily activity for each species in our study. Bars represent $95 \%$ confidence intervals and bars that do not cross the 0 axis indicate significant effects of noise on species activity. Asterisk (*) on California quail indicates a model that failed to converge or produce confidence intervals. 


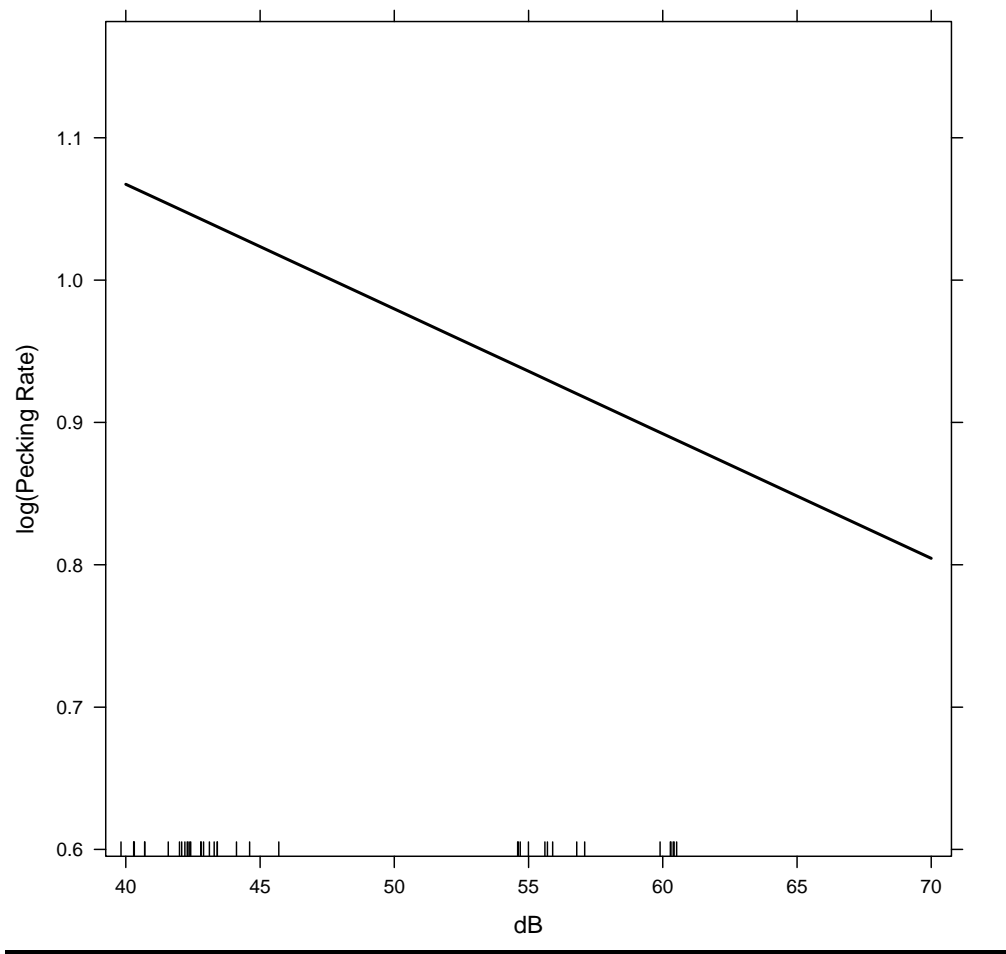

Figure 8: Pecking rate of white-crowned sparrows in relation to background sound level $(\mathrm{dB}(\mathrm{A}))$. The shaded band represents a $95 \%$ confidence interval. 


\section{REFERENCES}

Abbott, L. C., TAFf, D., Newman, P., Benfield, J., And Mowen, A. (2016). The INFLUENCE OF NATURAL SOUNDS ON ATTENTION RESTORATION. JOURNAL OF PARK AND RECREATION ADMINISTRATION, 34(3), 5-15.

BARber, J. R., CroOKS, K. R., AND Fristrup, K. M. (2009). ThE COSTS OF CHRONIC NOISE EXPOSURE FOR TERRESTRIAL ORGANISMS. TRENDS IN ECOLOGY AND EVOLUTION, 25(3), 180-189.

BARBER, J.R., CROOKS, K.R., AND FristruP, K.M. (2010). THE COSTS OF CHRONIC NOISE EXPOSURE FOR TERRESTRIAL ORGANISMS. TRENDS IN ECOLOGY AND EVOLUTION, 25, 180-189.

Barber, J.R., Burdett, C., Reed, S., Warner, K., Formichella, C., Crooks, K., THEOBALD, D., AND FRISTRUP, K. (2011). ANTHROPOGENIC NOISE EXPOSURE IN PROTECTED NATURAL AREAS: ESTIMATING THE SCALE OF ECOLOGICAL CONSEQUENCES. LANDSCAPE ECOLOGY, 26, 1281-1295.

BASIL, J.A., KAMIL, A.C., BALDA, R. AND FITE, K.V . (1996). DIFFERENCES IN HIPPOCAMPAL VOLUME AMONG FOOD STORING CORVIDS. BRAIN BEHAV. EVOL., 47, 156-164.

BAtes, D., Maechler, M., Bolker, B., AND WAlKer, S. (2015). FitTing Linear Mixed-EFFects Models Using LME4. Journal OF Statistical SOFTware, 67(1), $1-48$.

BAYNe, E. M., HABIB, L., AND BOUTIN, S. (2008). IMPACTS OF CHRONIC ANTHROPOGENIC NOISE FROM ENERGY-SECTOR ACTIVITY ON ABUNDANCE OF SONGBIRDS IN THE BOREAL FOREST. CONSERVATION BIOLOGY.

Benfield, J.A., Bell, P.A., Troup, L.J., Soderstrom, N.C., 2010. Does ANTHROPOGENIC NOISE IN NATIONAL PARKS IMPAIR MEMORY? ENVIRON. BEHAV. 42, $693 \mathrm{E} 706$.

BENFIELD, J.A., TAFF, B.D., NEWMAn, P., SMYTH, J., 2014. NATURAL SOUND FACILITATES MOOD RECOVERY FROM STRESS. ECOPSYCHOLOGY 6, 183E188.

Blomberg, S. P., Garland T. JR., And IVES, A. R. (2003). Testing FOR PHYLOGEnetiC SIGNAL IN COMPARATIVE DATA: BEHAVIORAL TRAITS ARE MORE LABILE. EVOLUTION 57, 717-745.

BLuMSTEIn, D.T. (2003). FLIGHT-INITIATION DisTANCE IN BIRDS IS DEPENDENT ON InTRuder StARTing Distance. The Journal of WiLDLIFE MANAGEMENT, 67, 852857. 
Blumstein, D.T., Anthony L.L., Harcourt R. And Ross G. (2003). Testing A Key ASSUMPTION OF WILDLIFE BUFFER ZONES: IS FLIGHT INITIATION DISTANCE A SPECIESSPECIFIC TRAIT? BIOLOGICAL CONSERVATION, 110, 97-100.

BLUMSTEIN, D.T. (2010). FLUSH EARLY AND AVOID THE RUSH: A GENERAL RULE OF ANTIPREDATOR BEHAVIOR? BEHAVIORAL ECOLOGY, 21, 440-442.

Blumstein, D.T., FernándeZ-Juricic, E., Zollner, P.A. And GArity, S. C. (2005). INTER-SPECIFIC VARIATION IN AVIAN RESPONSES TO HUMAN DISTURBANCE. JOURNAL OF APPLIED ECOLOGY, 42, 943-953.

Boersma, K. S., Nickerson, A., Francis, C. D., And SiePielski, A. M. (2016). Climate EXTREMES ARE ASSOCIATED WITH INVERTEBRATE TAXONOMIC AND FUNCTIONAL COMPOSITION IN MOUNTAIN LAKES. ECOL. EVOL. 6, 8094-8106.

Bratman, G.N., HAMILTON, J.P. AND DAILy, G.C. (2012). ThE IMPACTS OF NATURE EXPERIENCE ON HUMAN COGNITIVE FUNCTION AND MENTAL HEALTH. ANNALS OF THE NEW YORK ACADEMY OF SCIENCES, 1249, 118-136.

Bunkley, J. P., Mcclure, C. J. W., Kawahara, A. Y., Francis, C. D., And B arber, J. R. (2017). ANTHROPOGENIC NOISE CHANGES ARTHROPOD ABUNDANCES. ECOLOGY AND EVOLUTION, 2977-2985.

Buxton, R.T., McKenna, M.F., Mennitt, D., Fristrup, K., Crooks, K., Angeloni, L., WITTEMYER, G., 2017. NOISE POLLUTION IS PERVASIVE IN U.S. PROTECTED AREAS. SCIENCE, 356, 531-533.

CADE, B. (2015). MODEL AVERAGING AND MUDDLED MULTIMODAL INFERENCES. ECOLOGY, 96, 2370-2382.

CARVER, E. (2013). BIRDING IN THE UNITED STATES: A DEMOGRAPHIC AND ECONOMIC ANALYSIS: ADDENDUM TO THE 2011 NATIONAL SURVEY OF FISHING, HUNTING AND WILDLIFE-ASSOCIATED RECREATION. DIVISION OF FEDERAL AID, US FISH AND WILDLIFE SERVICE.

Chan, A.A.Y.-H., Giraldo-Perez, P., Smith, S., And Blumstein, D.T. (2010A). ANTHROPOGENIC NOISE AFFECTS RISK ASSESSMENT AND ATTENTION: THE DISTRACTED PREY HYPOTHESIS. BIOLOGY LETTERS, 6, 458-461.

Chan, A.A.Y.-H., Stahlman, W.D., Garlick, D., Fast, C.D., Blumstein, D.T., AND BLAISDELL, A.P. (2010B) INCREASED AMPLITUDE AND DURATION OF ACOUSTIC STIMULI ENHANCE DISTRACTION. ANIMAL BEHAVIOUR, 80, 1075-1079.

The Cornell Lab of ORnithology (2016). Winter BiRd Highlights, in FOCUS ON CITIZEN SCIENCE VOL. 12. HTTPS://FEEDERWATCH.ORG/WP- 
CONTENT/UPLOADS/2016/09/WINTERBIRDHIGHLIGHTS2016.PDF

Ellison, W. T., Southall, B. L., Clark, C. W., And Frankel, A. S. (2012). A NeW

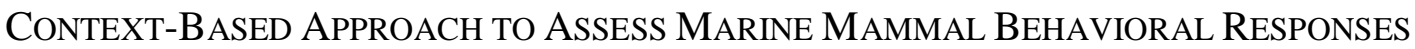
TO ANTHRopogenic SOUNDS. ConsERVATION BIOLOGY, 26(1), 21-28.

EHRliCh, P.R., DobKin, D.S., AND WheYe, D. (1988) THE BIRDER'S HANDBOOK: A FIELD GUIDE TO THE NATURAL HISTORY OF NORTH AMERICAN BIRDS INCLUDING ALL SPECIES THAT REGULARLY BREED NORTH OF MEXICO. NEW YORK: SIMON AND SCHUSTER.

EMERY, N.J., AND ClAYTON, N.S. (2004) THE MENTALITY OF CROWS: CONVERGENT EVOLUTION OF INTELLIGENCE IN CORVIDS AND APES. SCIENCE, 306, 1903-1907.

FAITh, D. P., Minchin, P. R., AND BELbin, L. (1987). COMPOSITIONAL DisSiMILARITY AS A ROBUST MEASURE OF ECOLOGICAL DISTANCE. VEGETATIO, 69, 57-68.

FERnÁNDEZ-JuRICIC, E., JiMENEZ, M.D. AND LuCAS, E. (2002). FACTORS AFFECTING INTRA- AND INTER-SPECIFIC VARIATIONS IN THE DIFFERENCE BETWEEN ALERT DISTANCES AND FLIGHT DISTANCES FOR BIRDS IN FORESTED HABITATS. CANADIAN JOURNAL OF ZOOLOGY, 80, 1212-1220.

Fernández-Juricic, E., Gall, M.D., Dolan, T., Tisdale, V. And Martin, G.R. (2008). THE VISUAL FIELDS OF TWO GROUND-FORAGING BIRDS, HOUSE FINCHES AND HOUSE SPARROWS, ALLOW FOR SIMULTANEOUS FORAGING AND ANTI-PREDATOR VIGILANCE. IBIS, 150, 779-787.

FernándeZ-Juricic, E., O’Rourke, C. AND Pitlik, T. (2010). Visual COVERAGE AND SCANNING BEHAVIOR IN TWO CORVID SPECIES: AMERICAN CROW AND WESTERN SCRUB JAY. JOURNAL OF COMPARATIVE PHYSIOLOGY A, 196, 879-888.

Fernández-Juricic, E., Gall, M.D., Dolan, T., O’Rourke, C., ThOMas, S. AND LYNCH, J.R. (2011). VISUAL SYSTEMS AND VIGILANCE BEHAVIOUR OF TWO GROUNDFORAGING AVIAN PREY SPECIES: WHITE-CROWNED SPARROWS AND CALIFORNIA TOWHEES. ANIMAL BEHAVIOUR, 81, 705-713.

FRANCIS, C. D., AND B ARBER, J. R. (2013). A FRAMEWORK FOR UNDERSTANDING NOISE IMPACTS ON WILDLIFE: AN URGENT CONSERVATION PRIORITY. FRONTIERS IN ECOLOGY AND THE ENVIRONMENT, 11, 305-313.

Francis, C. D., Ortega, C. P., And Cruz, A. (2009). Noise Pollution Changes Avian COMMUNITIES AND SPECIES INTERACTIONS. CURRENT BIOLOGY, 19, 1415-1419.

FRANCIS, C. D. (2015). VOCAL TRAITS AND DIET EXPLAIN AVIAN SENSITIVITIES TO ANTHROPOGENIC NOISE. GLOBAL CHANGE BIOLOGY, 21, 1809-1820.

Francis, C.D., PARITSIS, J., ORTEGA, C.P. AND CRUZ, A. (2011). LANDSCAPE PATTERnS 
OF AVIAN HABITAT USE AND NEST SUCCESS ARE AFFECTED BY CHRONIC GAS WELL COMPRESSOR NOISE. LANDSCAPE ECOLOGY, 26, 1269-1280.

Francis, C. D., Newman, P., TafF, B. D., White, C., Monz, C. A., Levenhagen, M., Petrelli, A.R., AbBott, L.C., Newton, J., Burson, S., CoOPer, C.B., Fristrup, K.M., McClure, C.J.W., MennitT, D., Giamellaro, M., Barber, J. R. (2017). ACOUSTIC ENVIRONMENTS MATTER: SYNERGISTIC BENEFITS TO HUMANS AND ECOLOGICAL COMMUNITIES. JOURNAL OF ENVIRONMENTAL MANAGEMENT, 203, 245254.

FRID, A., AND DILL, L. (2002). HUMAN-CAUSED DISTURBANCE STIMULI AS A FORM OF PREDATION RISK. CONSERVATION ECOLOGY, 6, 11.

GALl, M. D., AND FERNÁNDEZ-JURICIC, E. (2009). VisuAL FIELDS, EYE MOVEMENTS, AND SCANNING BEHAVIOR OF A SIT-AND-WAIT PREDATOR, THE BLACK PHOEBE (SAYORNIS NIGRICANS). JOURNAL OF COMPARATIVE PHYSIOLOGY A, 196, 15-22.

GILL, F.B., 2007. ORNITHOLOGY. MACMILLAN.

HAAS, G.E., AND WAKEFIELD, T.J. (1998). NATIONAL PARKS AND THE AMERICAN PUBLIC: A NATIONAL PUBLIC OPINION SURVEY ON THE NATIONAL PARK SYSTEM: A SUMMARY REPORT (CONDUCTED BY COLORADO STATE UNIVERSITY).

Halfwerk, W., Holleman, L. J. M., Lessells, C. K. M., And SlabbeKoorn, H. (2011). NEGATIVE IMPACT OF TRAFFIC NOISE ON AVIAN REPRODUCTIVE SUCCESS. JOURNAL OF APPLIED ECOLOGY, 48, 210-219.

HARRISON, X. A. (2014). USING OBSERVATION-LEVEL RANDOM EFFECTS TO MODEL OVERDISPERSION IN COUNT DATA IN ECOLOGY AND EVOLUTION. PEERJ, 2, E616.

IVES, A. R., Midford, P. E., AND GARLAND, T. J. (2007). Within-SPECIES VARIATION and Measurement ERror in Phylogenetic Comparative Methods. SystematiC BIOLOGY, 56, 252-270.

JONES, D. N. AND REYNOLDS, J. S. (2008), FEEDING BIRDS IN OUR TOWNS AND CITIES: A GLOBAL RESEARCH OPPORTUNITY. JOURNAL OF AVIAN BIOLOGY, 39, 265-271.

KAPLAN, R., AND KAPLAN, S. (1989). THE EXPERIENCE OF NATURE: A PSYCHOLOGICAL PERSPECTIVE. CUP ARCHIVE.

KARDOUS, C., AND SHAW, P. (2014). EVALUATION OF SMARTPHONE SOUND MEASUREMENT APPLICATIONS. THE JOURNAL OF THE ACOUSTICAL SOCIETY OF AMERICA, 135, EL186-EL192.

Kight, C. R., SAHa, M. S., Swaddle, J. P., And Swaddle1, J. P. (2012). ANTHROPOGENIC NOISE IS ASSOCIATED WITH REDUCTIONS IN THE PRODUCTIVITY OF 
BREEDING EASTERN BLUEBIRDS (SIALIA SIALIS). ECOLOGICAL APPLICATIONS ECOLOGICAL APPLICATIONS, 22, 1989-1996.

Kleist, N. J., Guralnick, R. P., CruZ, A., AND Francis, C. D. (2017). Sound SETTLEMENT: NOISE SURPASSES LAND COVER IN EXPLAINING BREEDING HABITAT SELECTION OF SECONDARY CAVITY-NESTING BIRDS. ECOLOGICAL APPLICATIONS, 27, 260-273.

Korner-Nievergelt, F., Roth, T., von Felten, S., Guelat, J., Almasi, B., And KORNER-NIEVERGELT, P. (2015)._BAYESIAN DATA ANALYSIS IN ECOLOGY USING LINEAR MODELS WITH R, BUGS AND STAN_. ELSEVIER.

KRAUSE J. AND GODIN J.-G. J. (1996). INFLUENCE OF PREY FORAGING POSTURE ON FLIGHT BEHAVIOR AND PREDATION RISK: PREDATORS TAKE ADVANTAGE OF UNWARY PREY. BEHAVIORAL ECOLOGY, 7, 264-271.

LA ROUCH G. P. (2003). BIRDING IN THE UNITED STATES: A DEMOGRAPHIC AND ECONOMIC ANALYSIS: ADDENDUM TO THE 2001 NATIONAL SURVEY OF FISHING, HUNTING AND WILDLIFE-ASSOCIATED RECREATION. DIVISION OF FEDERAL AID, US FISH AND WILDLIFE SERVICE.

LEPAGE, D., AND Francis, C. M. (2002). Do FEEDER Counts RELIABly INDiCATE BIRD Population CHANGES? 21 YEARS OF Winter BiRd COUNTS IN ONTARIO, CANADA. THE CONDOR, 104, 255-270.

LIMA S.L. AND BEDNEKOFF P.A. (1999). BACK TO THE BASICS OF ANTIPREDATORY VIGILANCE: CAN NONVIGILANT ANIMALS DETECT ATTACK? ANIMAL BEHAVIOUR, 58, $537-543$.

LYNCH E., JOYCE D. AND FRISTRUP K. (2011). AN ASSESSMENT OF NOISE AUDIBILITY AND SOUND LEVELS IN US NATIONAL PARKS. LANDSCAPE ECOLOGY, 26, 1297-1309.

Magnusson, A., Skaug, H., Nielsen, A., Berg, C., Kristensen, K., Maechler, M., VAN BENTHAM, K., BOLKER, B., AND BROOKS, M. (2017). GLMMTMB: GENERALIZED LiNEAR MiXed MODELS USING TEMPLATE MODEL BUILDER. R PACKAGE VERSION 0.1.1. HTTPS://CRAN.R-PROJECT.ORG/PACKAGE=GLMMTMB

MARTin, S. G. (2002). BREWER'S BlaCKBIRD (EUPHAGUS CYANOCEPHALUS). IN THE BiRdS OF North AmericA, No. 616 (A. PoOle, Ed.). In The Birds of North AMERICA ONLINE, ITHACA, NEW YORK.

MARIN L.D., NEWMAN P., MANNING R., VASKe J.J. AND StaCK D. (2011). Motivation AND ACCEPTABILITY NORMS OF HUMAN-CAUSED SOUND IN MUIR WOODS NATIONAL MONUMENT. LEISURE SCIENCES, 33, 147-161.

MASON J.T., MCCLURE C.J. AND BARBER J.R. (2016). ANTHROPOGENIC NOISE IMPAIRS 
OWL HUNTING BEHAVIOR. BIOLOGICAL CONSERVATION, 199, 29-32.

McClure, C. J. W., Ware, H. E., Carlisle, J., Kaltenecker, G., B ARber, J. R., AND BARBER, J. R. (2013). AN EXPERIMENTAL INVESTIGATION INTO THE EFFECTS OF TRAFFIC NOISE ON DISTRIBUTIONS OF BIRDS: AVOIDING THE PHANTOM ROAD. PROCEEDINGS OF THE RoYAl SOCIETY B: BIOLOGICAL SCIENCES, 280, 1773.

MennitT, D., FristruP, K.M., Sherrill, K., Nelson, L., 2013. MAPPing SOUND PRESSURE LEVELS ON CONTINENTAL SCALES USING A GEOSPATIAL SOUND MODEL. IN: PROCEEDINGS OF INTER-NOISE, INNSBRUCK, AUSTRIA, PP. 1-11.

Møller A., Tryjanowski P., Díaz M., Kwiecinski Z., IndyKIEWicz P., Mitrus C., GOLAWSKI A. AND POLAKOWSKI M. (2015). URBAN HABITATS AND FEEDERS BOTH CONTRIBUTE TO FLIGHT INITIATION DISTANCE REDUCTION IN BIRDS. BEHAVIORAL ECOLOGY, 26, 861-865.

Newman P., Taft D., Weinzimmer D., Lawson S., Trevino K., Fristrup K. AND MCKENNA M. (2013). MONITORING AND MANAGING ANTHROPOGENIC NOISE IN NATIONAL PARKS: LESSONS LEARNED FROM FIELD AND LABORATORY STUDIES. PAGES 6001-6008. INTER-NOISE AND NOISE-CON CONGRESS AND CONFERENCE PROCEEDINGS. INSTITUTE OF NOISE CONTROL ENGINEERING.

Oksanen, J., Kindt, R., Legendre, P., O’Hara, B., Simpson, G. L., Sólymos, P., SteVEns, M. H. H., WAGNER, H. (2008). VEGAN: CoMMUnity ECOlOGy PACKAGE. R PACKAGE VERSION 1.15-1, URL HTTP: //CRAN.R-PROJECT.ORG/PACKAGE=VEGAN

OKSANEN, J., KINDT, R., AND SimPSON, G. L. (2017). VEGAN3D: STATIC AND DYNAMIC 3D PLOTS FOR THE 'VEGAN' PACKAGE. R PACKAGE VERSION 1.1-0. HTTPS://CRAN.RPROJECT.ORG/PACKAGE=VEGAN3D

ORTEGA C.P. AND FRANCIS C.D. (2012). EFFECTS OF GAS WELL COMPRESSOR NOISE ON ABILITY TO DETECT BIRDS DURING SURVEYS IN NORTHWEST NEW MEXICO. ORNITHOLOGICAL MONOGRAPHS, 49, 78-90.

Otis, D. L., Schulz, J. H., Miller, D., Mirarchi, R. E., AND Baskett, T. S. 2008. MoURning Dove (ZENAIDA MACROURA). IN THE BIRDS OF NORTH AMERICA, NO. 117 (A. Poole, Ed.). The Birds of North America Online, ITHACA, New York.

PACIFICI K., Simons T.R. And Pollock K.H. (2008). EFFECTS OF VEGETATION AND BACKGROUND NOISE ON THE DETECTION PROCESS IN AUDITORY AVIAN POINT-COUNT SURVEYS. AUK, 125, 600-607.

PAGEL, M. (1999). INFERRING THE HISTORICAL PATTERNS OF BIOLOGICAL EVOLUTION. NATURE, 401, 877-884.

Petrelli, A. R., LeVenhagen, M. J., Wardle, R., Barber, J. R., And Francis, C. D. 
(2017). FiRST to Flush: THE EFFECTS OF AMBIENT NOISE ON SONGBIRD FLIGHT INITIATION DISTANCES AND IMPLICATIONS FOR HUMAN EXPERIENCES WITH NATURE. FRONTIERS IN ECOLOGY AND EVOLUTION, 5, 67.

QuinN J.L., WhitTingham M.J., BUtLER S.J. AND CRESSWELL W. (2006). NOISE, PREDATION RISK COMPENSATION AND VIGILANCE IN THE CHAFFINCH FRINGILLA COELEBS. JOURNAL OF AVIAN BIOLOGY, 37, 601-608.

RATCLIFFE E., GATERSLEBEN B. AND SOWDEN P.T. (2013). BIRD SOUNDS AND THEIR CONTRIBUTIONS TO PERCEIVED ATTENTION RESTORATION AND STRESS RECOVERY. JOURNAL OF ENVIRONMENTAL PSYCHOLOGY, 36, 221-228.

REVELL, L. J. (2012) PHYTOOLS: AN R PACKAGE FOR PHYLOGENETIC COMPARATIVE BIOLOGY (AND OTHER THINGS). METHODS ECOL. EVOL., 3, 217-223.

SENTER, P., 2008. VoICES OF THE PAST: A REVIEW OF PALEOZOIC AND MESOZOIC ANIMAL SOUNDS: REVIEW. HIST. BIOL. 20, 255E287.

SenZaKi M., YAmaURa Y., Francis C.D. AND NAKAMURA F. (2016). TRAFFIC NOISE REDUCES FORAGING EFFICIENCY IN WILD OWLS. SCIENTIFIC REPORTS, 6, 30602.

Shannon, G., Crooks, K. R., Wittemyer, G., AND Fristrup, K. M. (2016A). RoAD NOISE CAUSES EARLIER PREDATOR DETECTION AND FLIGHT RESPONSE IN A FREERANGING MAMMAL. BEHAVIORAL ECOLOGY, 25, 1370-1375.

Shannon, G., Mckenna, M. F., Angeloni, L. M., Crooks, K. R., Fristrup, K. M., BROWN, E., ET AL. (2016B). A SYNTHESIS OF TWO DECADES OF RESEARCH DOCUMENTING THE EFFECTS OF NOISE ON WILDLIFE. BIOL. REV. 24, 982-1005.

SimPSON S.D., RADFORD A.N., NedeleC S.L., FerRARI M.C.O., Chivers D.P., MCCORMICK M.I. AND MEEKAN M.G. (2015). ANTHROPOGENIC NOISE INCREASES FISH MORTALITY BY PREDATION. NATURE COMMUNICATIONS, 7, 10544.

Stansfeld, S. A., B. Berglund, C. Clark, I. LOPez-B ARrio, P. Fischer, E. OHRSTRÖM, M. M. HAINES, J. HEAD, S. HYGGe, I. VAN KAMP, B. F. BERRY, AND RANCH STUDY TEAM. 2005. AIRCRAFT AND ROAD TRAFFIC NOISE AND CHILDREN'S COGNITION AND HEALTH: A CROSS-NATIONAL STUDY. THE LANCET, 365,1942-1949.

SyMONDS, M.R.E., WeSTON, M.A., VAN DONGEN, W.F.D., LILl, A., Robinson, R.W., AND GUAY, P.-J., 2016. TIME SINCE URB ANIZATION BUT NOT ENCEPHALISATION IS ASSOCIATED WITH INCREASED TOLERANCE OF HUMAN PROXIMITY IN BIRDS. FRONTIERS IN ECOLOGY AND EVOLUTION, 4.

US FISH AND WILDLIFE SERVICE (2016) 2015 NATIONAL SURVEY OF FISHING, HUNTING, AND WILDLIFE-ASSOCIATED RECREATION - NATIONAL OVERVIEW, HTTP://WSFRPROGRAMS.FWS.GOV/SUBPAGES/NATIONALSURVEY/NATIONAL_SURVEY. 
HTM

VAN KEMPEN, E., BABISCH, W., 2012. THE QUANTITATIVE RELATIONSHIP BETWEEN ROAD TRAFFIC NOISE AND HYPERTENSION: A META-ANALYSIS. J. HYPERTENS. 30, $1075 \mathrm{E} 1086$.

Ware, H. E., Mcclure, C. J. W., CARlisle, J. D., And Barber, J. R. (2015). A PHANTOM ROAD EXPERIMENT REVEALS TRAFFIC NOISE IS AN INVISIBLE SOURCE OF HABITAT DEGRAdATION. PROCEEDINGS OF THE NATIONAL ACADEMY OF SCIENCE U.S.A. 112, 12105-12109. 


\section{APPENDIX}

Supplementary Tables

Table A1: This table summarizes the effect of sound level and foraging guild-specific competition on species-specific daily activity. Bolded rows indicate species with strong effects. The asterisk indicates that the model for California quail (CAQU) failed to converge and does not have a lower confidence interval.

\begin{tabular}{|l|r|r|r|r|r|l|}
\hline Species & \multicolumn{1}{l|}{ Effect } & $\begin{array}{l}\text { Standard } \\
\text { Error }\end{array}$ & LCI & UCI & $\mathrm{n}$ & Guild \\
\hline EUCD & -0.084 & 0.3037 & -0.832678 & 0.441275 & 45 & Ground \\
\hline MODO & $\mathbf{0 . 9 7 8}$ & $\mathbf{0 . 2 8 9 3}$ & $\mathbf{0 . 4 0 1 4 2 7}$ & $\mathbf{1 . 6 0 2 1 0 5}$ & $\mathbf{2 9 0}$ & Ground \\
\hline DEJU & $\mathbf{- 0 . 1 4 4}$ & $\mathbf{0 . 0 7 9 1}$ & $\mathbf{- 0 . 3 4 2 8 5 3}$ & $\mathbf{- 0 . 0 3 1 9 7 2}$ & $\mathbf{2 9 7}$ & Ground \\
\hline LEGO & -0.697 & 0.4220 & -1.585078 & 0.139834 & 14 & Feeder \\
\hline WCSP & -0.073 & 0.1198 & -0.306441 & 0.179511 & 183 & Ground \\
\hline CASJ & 0.117 & 0.0042 & -0.386022 & 0.604417 & 26 & Ground \\
\hline HOFI & 0.351 & 0.3406 & -0.263152 & 1.085600 & 19 & Feeder \\
\hline CBCH & 0.035 & 0.3470 & -0.595005 & 0.636089 & 17 & Feeder \\
\hline CALT & 0.209 & 0.3511 & -0.541949 & 0.937508 & 16 & Ground \\
\hline SPTO & 0.009 & 0.3596 & -0.793350 & 0.716899 & 22 & Ground \\
\hline BRBA & $\mathbf{2 . 1 7 9}$ & $\mathbf{1 . 2 9 0 0}$ & $\mathbf{0 . 5 7 5 6 9 4}$ & $\mathbf{7 . 6 6 6 1 4 7}$ & $\mathbf{2 5}$ & Ground \\
\hline CAQU* & -0.296 & 0.9442 & & 2.320770 & 15 & Ground \\
\hline AMCR & -1.095 & 0.6836 & -2.767632 & 0.612082 & 5 & Ground \\
\hline WITU & -0.156 & 0.3581 & -0.887100 & 0.549473 & 13 & Ground \\
\hline
\end{tabular}


Table A2: This fixed effects table reports the influence of given variables on pecking rate of dark-eyed juncos. Presented are effect sizes, standard error, and $95 \%$ confidence intervals from a model including all predictors within 2 AICc. No parameter had a significant effect.

\begin{tabular}{|l|r|r|r|r|}
\hline & Estimate & \multicolumn{1}{|l|}{ Std. Error } & \multicolumn{1}{l|}{ Lower CI } & \multicolumn{1}{l|}{ Upper CI } \\
\hline (Intercept) & 0.93091 & 0.05763 & 0.8142528 & 1.0475716 \\
\hline scale(Activity) & -0.03231 & 0.03577 & -0.1047304 & 0.0401121 \\
\hline scale(dB) & 0.03635 & 0.04907 & -0.0629816 & 0.1356855 \\
\hline Treatment: Quiet & -0.04426 & 0.09628 & -0.2391795 & 0.1506543 \\
\hline
\end{tabular}

